\title{
LA COMUNICABILIDAD EN EL DERECHO PENAL CHILENO A PARTIR DE SU INTERPRETACIÓN PRÁCTICA. MIRADA CRÍTICA A SU FORMULACIÓN COMO "PRINCIPIO DEL DERECHO"*
}

[Communicability in chilean criminal law from their practical interpretation. Critical view to its formulation as "principle of law"]

\author{
Alejandro LeIva LóPEZ** \\ Universidad del Desarrollo
}

\begin{abstract}
RESUMEN
Se analiza el denominado principio de comunicabilidad en el Derecho penal chileno con particular atención a sus efectos, lo que se advierte especialmente a partir de un reciente fallo de la Corte Suprema que condena a los partícipes extraneus de un delito de fraude al Fisco como autores ejecutores. Se critica la consideración amplia de este supuesto principio, cuestionando tal cualidad y proponiendo criterios para su categorización como regla.

Palabras clave

Comunicabilidad - principios reglas - delitos especiales - autoría, participación.
\end{abstract}

\begin{abstract}
The paper analyzes the principle of communicability in Chilean criminal law, especially from a recent conviction verdict of the chilean Supreme Court that erroneously condemns the participants in a "staff member crime" as direct perpetrators. The article criticizes the principle category of communicability and raises hypotheses for its categorization as a rule.

KEY WORDS

Communicability - principles rules - special crimes - perpetrators - participants.
\end{abstract}

Recibido el 18 de julio y aceptado el 1 de diciembre de 2017

* * El presente trabajo corresponde a la habilitación para obtener el grado de Doctor en Derecho sustentado por la Beca Doctorado Nacional, Comisión Nacional de Investigación Científica y Tecnológica.

** Magíster en Derecho Penal. Profesor de Derecho Penal de la Facultad de Derecho de la Universidad del Desarrollo. Dirección postal Avda. Plaza 700, Las Condes, Santiago, Chile. Correo electrónico aleival@udd.cl 


\section{INTRODUCCIÓN}

El llamado principio de comunicabilidad en materia penal se suele invocar para resolver problemas de imputación entre autores y partícipes — en sentido estricto y aun amplio o intervinientes — , siendo un área especialmente problemática para el Derecho penal la de los denominados delitos especiales y, en particular, la determinación del título de castigo aplicable a terceros o extraneus que no detentan la calidad especial exigida en el tipo. En este sentido, coexisten diversas tesis sobre su alcance y contenido.

Pese a su uso extendido, la calidad de principio del Derecho con que se vincula a la comunicabilidad no ha sido cuestionada y en general se le ha reconocido doctrinal y jurisprudencialmente, quizás de manera inconsciente ${ }^{1}$, dicha cualidad, ampliándose indebidamente sus efectos.

Sin ir más lejos y en sentencia de 2015, la Corte Suprema ${ }^{2}$ —aplicando la comunicabilidad como principio-condenó a los intervinientes no funcionarios o extraneus de un delito de fraude al Fisco, como autores ejecutores del mismo, sin reparar en las consecuencias de dicha categorización. En efecto, existen considerables aspectos que atender para determinar la calidad de principio de la comunicabilidad o su eventual cualidad diversa e importantes efectos que de ello se derivan, entre otros, determinar el sentido y alcance de la norma del Código donde se expresaría la comunicabilidad —en específico, el artículo 64-, con incidencia en

1 Así, véase Novon, Eduardo, Curso de Derecho Penal chileno, Parte General (Santiago, Editorial Jurídica de Chile, 1960), II, pp. 210 y ss.; Etcheberry, Alfredo, Derecho Penal. Parte General (3. ${ }^{a}$ edición, revisada y actualizada, Santiago, Editorial Jurídica de Chile, 1998), II, p. 81 y ss.; MaÑalich, Juan Pablo, ¿Discrecionalidad judicial en la determinación de la pena en caso de concurrencia de circunstancias atenuantes de la responsabilidad penal?, en Departamento de Estudios (Defensoría Penal Pública) (2009), p. 11, nota 21. [visible en internet: http://www.biblio.dpp.cl/biblio/DataBank/3767-2.pdf]; Rodríguez Collao, Luis, El principio de comunicabilidad en el ámbito de los delitos funcionarios, en Repositorio Digital del Fondo Nacional de Desarrollo Científico y Tecnológico (2004), FONDECYT; [visible en internet: http://dspace2.conicyt.cl/ handle/10533/60566]; Cury, Enrique, Derecho Penal. Parte General (2. ${ }^{a}$ ed., Santiago, Editorial Jurídica de Chile, 1992), II, pp. 229 y ss., este último quien se refiere al principio de la incomunicabilidad. Asimismo, lo catalogan como principio: SCS, causa Rol N 4513-2010, de fecha 16 de octubre de 2010; SCS, causa Rol $\mathrm{N}^{\circ}$ 9779-2010, de fecha 20 de abril de 2011; SCA de Talca, causa Rol N 441-2016, de fecha 11 de julio de 2016; SCA de Concepción, causa Rol Nº152 de 2015, de fecha 27 de marzo de 2015; SCA de Concepción, causa Rol N 566-2010, de fecha 13 de diciembre de 2010; SCA de Valparaíso, causa Rol N 1182-2013, de fecha 30 de septiembre de 2013.

2 SCS, causa Rol № 17014-2015 de fecha 17 de diciembre de 2015. 
la precisión de la participación para delitos especiales concretos y, consecuencialmente, la pena aplicable a cada uno de los autores y partícipes.

El examen de este sentido de la comunicabilidad parece adquirir mayor importancia en la época actual, conocida por algunos como "la era de los principios”’. Así, basta con revisar cómo se ha recurrido de manera creciente a la institución de los principios en la legislación nacional. Cuerpos normativos e incluso códigos los han tipificado o positivado de manera expresa.

Principios como el debido proceso, irretroactividad de la ley penal, legalidad, inocencia, entre otros, se encuentran expresamente consagrados en la Constitución Política de la República, en los artículos inaugurales del Código Procesal Penal, o incluso en leyes especiales, donde la práctica parece generalizada, al menos en el derecho nacional ${ }^{4}$.

Los principios jurídicos son cada vez más usados por los estudiosos del Derecho y tribunales, tanto ordinarios como especiales — mírese solo el caso del Tribunal Constitucional ${ }^{5}$ - Incluso los funcionarios de la Ad-

${ }^{3}$ De manera reciente, la Universidad Alberto Hurtado organizó un seminario denominado "La era de los principios", un encuentro en el que importantes juristas nacionales y extranjeros participaron y del cual surgió la obra Principios jurídicos, análisis y crítica en la que se discuten varios de los temas que aquí revisaremos.

${ }^{4}$ Véase, entre otros, el caso de la Ley N. ${ }^{\circ} 19.968$ que crea los tribunales de familia, la que en su artículo 16 consagra expresamente el denominado principio de interés superior del niño, el principio de no autoincriminación del artículo 37, y los principios de igualdad, voluntariedad, confidencialidad e imparcialidad asociados a las normas sobre mediación de los artículos 105 y siguientes. Por su parte, la Ley N. ${ }^{\circ} 20.084$ sobre Responsabilidad Penal Adolescente (RPA), recurre a la misma técnica, tipificando el denominado principio de separación de los adolescentes privados de libertad respecto de la población penal adulta, ello en el artículo 48. Y, como ejemplo paradigmático, el Código del Trabajo que, consagra positivamente, entre otros, los principios de igualdad de remuneraciones entre hombres y mujeres del artículo 62 bis; o el principio de buena fe en la negociación colectiva del artículo 403.

${ }^{5}$ V. gr., y en cuanto al principio de legalidad o reserva, véanse: STC, Rol $\mathrm{N}^{\circ}$ 2990, de fecha 10 de enero de 2017; STC, Rol N² 2988, de fecha 29 de diciembre de 2016; STC, Rol N 3065, de fecha 27 de diciembre de 2016; STC, Rol N 3091, de fecha 27 de diciembre de 2016; STC, Rol N 3035, de fecha 27 de diciembre de 2016; STC, Rol N 3141, de fecha 27 de diciembre de 2016; STC, Rol N 3008, de fecha 27 de diciembre de 2016; STC, Rol N 3052, de fecha 20 de diciembre de 2016; STC, Rol N² 2881, de fecha 15 de diciembre de 2016; STC, Rol N² 2874, de fecha 15 de noviembre de 2016. En cuanto al principio de nullum crimen sine lege, entre otras: STC, Rol N 2953, de fecha 4 de octubre de 2016; STC, Rol N 2922, de fecha 29 de septiembre de 2016; STC, Rol N² 2744, de fecha 8 de octubre de 2015; STC, Rol N ${ }^{\circ}$ 2673, de fecha 1 de octubre de 2015; STC, Rol N²648, de fecha 7 de septiembre de 2015; STC, Rol N 2615, de fecha 30 de octubre de 2014; STC, Rol Nº 1973, de 
ministración vuelven con creciente frecuencia a éstos en sus dictámenes y resoluciones. No en vano Squella ha afirmado que "(...) asistimos a una rehabilitación de los principios, e incluso, a un auténtico auge de ellos".

En concreto, se ha hablado de un "auge principialista"7 a partir de las obras de Dworkin y Alexy. El primero, en The Model of Rules ${ }^{8}$ y antes en Judicial Discretion ${ }^{9}$, distinguió entre principios y reglas, y el segundo, en su Teoría de la Argumentación Jurídica ${ }^{10}$ y en su Teoría de los Derechos Fundamentales $^{11}$, formula los principios como mandatos de optimi-

fecha 3 de noviembre de 2011; STC, Rol N 1584, de fecha 17 de junio de 2010; STC, Rol No 559, de fecha 7 de junio de 2007; STC, Rol N 468, de fecha 9 de diciembre de 2006. Asimismo, sentencias respecto al principio de non bis in idem, entre otras, ver, STC, Rol No 3000, de fecha 10 de enero de 2017; STC, Rol N²983, de fecha 13 de diciembre de 2016; STC, Rol N² 2896, de fecha 25 de agosto de 2016; STC, Rol No 2722, de fecha 15 de octubre de 2015; STC, Rol N 2744, de fecha 8 de octubre de 2015; STC, Rol N² 2702, de fecha 11 de junio de 2015; STC, Rol N 2346, de fecha 16 de enero de 2014; STC, Rol N² 2402, de fecha 26 de noviembre de 2013; STC, Rol N 2403, de fecha 8 de noviembre de 2013; STC, Rol No 2133, de fecha 4 de julio de 2013.

${ }^{6}$ Squella, Agustín, Principios jurídicos y positivismo jurídico, en Carbonell, Flavia; Coloma, Rodrigo; Letelier, Raúl (coordinadores), Principios Jurídicos, análisis y crítica (Santiago, Editorial Thompson Reuters, 2011), p. 26.

7 Carbonell, Flavia - Coloma, Rodrigo - Letelier, Raúl (coordinadores), Principios Jurídicos, análisis y crítica, Prólogo, (Santiago, Editorial Thompson Reuters, Chile, 2011), p. XIV.

${ }^{8}$ Dworkin, Ronald, The Model of Rules, en The University of Chicago Law Review 1 (1967) 35, p. 14.[visible en internet: http://chicagounbound.uchicago.edu/uclrev/ vol35/iss1/3/].

${ }^{9}$ Dworkin, Ronald, Judicial Discretion, en The Journal of Philosophy 60 (1963) 21, p. 624. [visible en internet:

https://www.pdcnet.org/pdc/bvdb.nsf/purchase?openform\&fp=jphil\&id=jphil_1963_0060_0021_0624_0638].

${ }^{10}$ Alexy, Robert, Teoría de la Argumentación Jurídica (traducción de Manuel Atienza e Isabel Espejo, Madrid, Centro de Estudios Constitucionales, 1997).

${ }^{11}$ Alexy, Robert, Teoría de los derechos fundamentales (traducción de Carlos Bernal Pulido, Madrid, Centro de Estudios Constitucionales, 1993). Los principios serían, pues, "mandatos de optimización", que se caracterizan por el hecho de que pueden ser cumplidos en diferente grado y porque la medida debida de su cumplimiento no sólo depende de las posibilidades reales, sino también de las posibilidades jurídicas; estas últimas vienen determinadas por los principios y reglas que juegan en sentido opuesto (al principio en cuestión). Por el contrario, las reglas son normas que exigen un cumplimiento pleno y, en ese sentido, sólo pueden ser cumplidas o incumplidas. "Si una regla es válida, entonces debe hacerse exactamente lo que ella exige, ni más ni menos. Por lo tanto, las reglas contienen determinaciones en el ámbito de lo fáctica y jurídicamente posible. Esto significa - concluye Alexy- que la diferencia entre reglas y principios es cualitativa y no de grado. Toda norma es o bien una regla o un principio". 
zación, es decir, como normas que ordenan que algo sea realizado en la mayor medida posible, dentro de las posibilidades jurídicas y reales existentes.

Por otra parte, nuestros tribunales superiores de justicia han debido, especialmente por el auge de los mismos, avocarse a su conocimiento y a darles aplicación a casos concretos en que se reclama su intervención.

Así, y volviendo al fallo comentado, la Corte Suprema condenó a los intervinientes no cualificados como autores ejecutores de un delito de fraude al Fisco, aplicando la calidad de autores del $15 \mathrm{~N}^{\circ} 1$ del Código Penal en virtud del principio de comunicabilidad. La sentencia de primera instancia dictada por el Tribunal Oral en lo Penal (TOP de Los Andes), condena a los acusados particulares o extraneus a la pena efectiva de 10 años y un día de presidio mayor en su grado medio.

En este sentido, la sentencia del TOP de Los Andes en su considerando cuadragésimo sexto, señaló que:

La calidad de funcionario público, en los delitos especiales impropios se comunica a los autores en que concurran, tanto si integran el tipo penal, como si no lo integran, quedando todos los participes regidos por la única figura penal aplicable. En el caso del fraude al Fisco, la circunstancia personal de ser empleado público integra el tipo delictivo, de manera tal que ella se comunica a los copartícipes que estaban en conocimiento de ella $a^{12}$.

La imprecisa y extendida aplicación de la comunicabilidad llama la atención ${ }^{13}$. El tribunal reconoce la distinción entre delitos especiales propios e impropios, pese a lo cual no aplica sus efectos ${ }^{14}$. A los delitos

12 TOP Los Andes, causa RIT N 18-2015, de fecha 19 de septiembre de 2015.

${ }^{13}$ Con crítica similar a este raciocinio de la Corte contenido en fallos anteriores, FERDMAN, Jorge, ¿De qué puede hacerse responsable al extraneus, concurrente a la comisión de un delito que requiere autor calificado? Comentario a propósito de algunos pronunciamientos jurisprudenciales chilenos en el ámbito de los delitos con sujeto activo calificado, en VAN WEEZEL, Alex (editor), Humanizary renovar el Derecho penal. Estudios en memoria de Enrique Cury (Santiago, Legal Publishing, 2013), pp. 679 y ss.

${ }^{14}$ En el mismo sentido y sin darle aplicación a esta distinción, los fallos: SCS, causa Rol N 5419-2003 de fecha 16 de octubre de 2006; SCS, causa Rol N² 25.37820014 de fecha 28 de junio de 2016; SCS, causa Rol N²321-2007 de fecha 19 de mayo de 2008, este último conocido como el caso MOP GATE que concluye en su considerando decimocuarto: "Que, a criterio de esta Corte Suprema, la calidad de funcionario público, en los delitos cualificados impropios, como lo es el fraude al fisco, castigado en el artículo 239 del Código Punitivo, se comunican a los autores en que concurran, tanto si integran el tipo penal, como si no lo integran, quedando todos los partícipes regidos por la única figura penal aplicable (...). Clave en esta reflexión resulta ser la determinación de si el tipo delictivo conserva o no su carácter de tal en el supuesto de eliminarse hipotéticamente la circunstancia personal de ser 
especiales impropios correspondería el fraude al Fisco y, a diferencia de los primeros, son aquellos en que existiría un tipo penal residual aplicable a sujetos no cualificados ${ }^{15}$.

Asimismo, la resolución concluye que bastaría que una circunstancia integre el tipo delictivo para que ésta se comunique, sin límites, tanto a coautores como partícipes, por el solo hecho de conocer dicha circunstancia, pese a catalogarla como personal.

Por otro lado, el fallo no distingue autores de partícipes en sentido

empleado público uno de los copartícipes, evento en el cual deberá concluirse que aquélla integra el correspondiente tipo $\mathrm{y}$, por tanto, se comunica a quienes estaban en conocimiento de ella. Tal es, precisamente, la hipótesis de la especie, por existir suficiente evidencia, en el proceso, del conocimiento que Herrera Labarca tenía de la relación estatutaria que vinculaba a sus coautores con la Administración del Estado, presupuesto de comunicabilidad que debe, por ende, considerarse concurrente". Pese a ello, el fallo cuenta con sensato voto disidente, el que, en su numeral $2^{\circ}$ señala: "Que, a consecuencia de ello, debe afirmarse -como observa con agudeza Cury en la última edición de su Derecho Penal, Parte General- que la citada disposición "surte sus efectos también para los tipos calificados impropios, respecto de los cuales, por consiguiente, las cualidades personales determinantes sólo de un incremento o disminución del injusto básico, no se comunican".

${ }^{15}$ En efecto, en los delitos especiales impropios la existencia de un tipo común subyacente permite dividir el título de imputación, sancionando al intraneus por el delito especial impropio - en el que la calidad especial es entendida como una mera agravante- y al extraneus por la figura común paralela. Ossandón WIDOw, María Magdalena, Delitos especiales y de infracción de deber en el Anteproyecto de Código Penal, en Politica Criminal. 1 (2006), A4, p. 2. En contra, MaÑalich, Juan Pablo, La malversación de caudales públicos y el fraude al fisco como delitos especiales, en Política Criminal 7 (2012) 14, pp. 357 y ss., para quien derechamente no existirán los delitos especiales "impropios", denominación que a su parecer hace explícita la impropiedad de semejante caracterización, catalogando el delito de fraude al Fisco como un delito especial de administración desleal y no como una forma de estafa o estafa agravada. 
estricto, pese a que la determinación típica de estos últimos es de naturaleza subsidiaria, y por tanto, merecedores de menor reproche penal ${ }^{16-17}$.

Desde el punto de vista doctrinal, el fallo analizado se podría situar al interior de las teorías denominadas como de comunicabilidad extrema. De acuerdo a esta postura, tanto intraneus como extraneus deben responder penalmente por el mismo título de castigo. En este sentido, la calificación del delito estaría dada por el autor (de acuerdo a los arts. 51 y ss. CP.), pues la conducta del extraneus partícipe carece de sentido si no se considera la conducta del autor principal intraneus. Finalmente, estas teorías extremas parten de la base de que, como el legislador regula sólo la incomunicabilidad de las circunstancias modificatorias sin referencia a los elementos integrantes del tipo, estos últimos serían comunicables ${ }^{18}$.

Siguiendo estos criterios, la comunicabilidad considerada como principio facultaría a un tribunal para transmitir toda clase de elementos integrantes de los tipos penales —aun cuando no se contemplen por el legislador como comunicables - a toda clase de autores e incluso partícipes en sentido estricto, sin distinción de si éstos son o no sujetos cualificados ${ }^{19}$.

Esto ocurre cuando el tribunal considera que la calidad de empleado

${ }^{16}$ En nuestro ordenamiento jurídico, esta característica se encuentra expresamente establecida para los cómplices y encubridores mediante las cláusulas de subsidariedad contenidas en los arts. 16 y 17, inc. primero, del CP. Es partícipe el que interviene dolosamente en el hecho ajeno sin concurrir a la ejecución de la conducta típica ni contar con el dominio de ella, a diferencia del autor, quien tiene dominio del acto, objetiva y subjetivamente. Cury, Enrique, Derecho Penal. Parte General (reimpresión 2. ${ }^{a}$ ed., Santiago, Editorial Jurídica de Chile, 1997), II, p. 243. Sin perjuicio de lo señalado, existe abundante literatura (a contar de Roxin), que busca darle solución a los problemas que generan los delitos especiales mediante los denominados delitos de infracción de deber (Pflichtdelikten), precisamente por la incapacidad de la teoría del dominio del hecho para dar solución a algunos de estos problemas. Sobre ello, volveremos más adelante.

${ }^{17}$ Como respecto de los coautores no rige el principio de accesoriedad, los coautores extraneus solo deberían responder por su propia conducta como autores del delito común o residual (estafa y no fraude al Fisco). Sin embargo, y en el fallo aludido, el tribunal tampoco distingue entre tipos de coautores y copartícipes, dándoles a todos igual tratamiento. En el mismo sentido: Vargas, Tatiana, Comunicabilidad de circunstancias personales, en Jurisprudencia al día 97 (2008), año 3, pp. 1149-1150.

${ }^{18}$ En paralelo, encontramos las teorías denominadas como incomunicabilidad limitada e incomunicabilidad extrema que trataremos más adelante.

${ }^{19}$ Como destaca Ferdman, Jorge, cit. (n. 13), p. 681, si alguna función desempeña la teoría de la imputación en materia penal, ella es la construcción de un sistema para determinar hasta dónde llegará la responsabilidad de cada una de las personas que concurran a la comisión de un delito, haciéndose cargo y resolviendo el diferencial de sanción que a cada quien corresponda. El concluir que todos son autores en 
público exigida en los delitos funcionarios es comunicable al extraneus, pese a tratarse de un elemento integrante del tipo y no de una circunstancia de las que el artículo 64 consagra como com unicable. Una interpretación y aplicación de tal extensión, creemos, vulnera abiertamente el principio nullum crimen sine lege ${ }^{20}$.

En este sentido, la discusión sobre la comunicabilidad de circunstancias o elementos típicos es relevante en cuanto a si puede o no estimarse que los autores o partícipes en sentido restringido — que no tienen la cualidad especial exigida por un tipo concreto- quedan ligados jurídicamente a la misma suerte y cualificación típica de aquellos autores o partícipes que sí poseen una cualidad típica. No en vano Novoa señalaba que esta problemática se plantea con frecuencia ante los tribunales y cobra, por ello, extraordinaria importancia práctica ${ }^{21}$.

De todo esto se concluye que el estudio de la comunicabilidad en materia penal enfrenta complejos desafíos en cuanto a su aplicación y límites, en particular si se funda en su calidad de principio jurídico que supone aplicación amplia y difusa, a diferencia de, por ejemplo, una regla, cuya aplicación sería más bien restringida y limitada.

En este trabajo se propone una nueva visión de la comunicabilidad en un plano distinto al de sus meros efectos. Se revisa críticamente la calidad de principio asociado a la comunicabilidad en Derecho penal y se postulan criterios para su posible categorización en consonancia con los principios de tipicidad, proscripción de la analogía e interpretación restrictiva de los tipos penales, con repercusión directa en la determinación de coautores y partícipes en delitos especiales.

Señalado lo anterior, pasaremos a revisar: $\imath$ ) el origen y regulación chilena del hasta ahora denominado principio de comunicabilidad (II); ii) las distintas posiciones dogmáticas que han pretendido darle solución a la comunicabilidad en el Derecho penal (III); iii) el concepto y aplicación

la misma medida y con igual grado de responsabilidad, pareciere una generalización no compatible con la singularización y diferenciación aludidas.

${ }^{20}$ Ya sabemos que todo aquello que no esté expresamente previsto en la ley penal como delictuoso no es punible, de modo que las lagunas legales que en este aspecto se produzcan corresponden a hechos no regidos por el Derecho penal. Otro tanto cabe decir de las penas, porque no puede ser impuesta ninguna sanción que exceda la que expresamente señaló la ley, aun cuando parezca que de parte de ésta hubo omisión u olvido. Aquellos esfuerzos — fundados, finalmente, en consideraciones de justicia material— que buscan dar solución a lagunas de punibilidad que suelen darse en casos de intervención de extraneus, particularmente en los delitos especiales propios, no pueden, sin más, soslayar principios fundamentales, como el de legalidad y sus derivaciones.

${ }^{21}$ NovoA, Eduardo cit. (n. 1), pp. 117 y ss. 
de los principios del Derecho y en especial en el Derecho penal (IV); y $i v)$ se discutirán los criterios generalmente aceptados para diferenciar principios de reglas y otras instituciones similares $(V)$.

\section{ARtículo 64 DEL CÓdigo PENAL y LA COMUNICABILIDAD}

Como es sabido, el Código penal tomó el actual artículo 64, sin mayores modificaciones, del artículo 69 del Código penal español de $1848^{22}$, que a su vez proviene de los artículos 76 y 77 del Código penal francés de 1810, conocido también como Código Napoleónico ${ }^{23}$.

${ }^{22}$ Sin un ánimo historicista y, a propósito de las actas de las sesiones de la Comisión Redactora chilena, este artículo fue tomado sin alteración del 69 del Código español, discutiéndose en la sesión 19: "pero la segunda parte que trata de la participación que pueden tener las circunstancias que consistan en la ejecución material del delito o de los medios que se empleen para ejecutarlo, $i$ que, en un último resultado, vienen a ser las que determinan la responsabilidad de cada uno de los co-reos, se convino después de alguna discusión entre los presentes, en que era necesario dejarlo integro, para que por él se tomaran en cuenta las circunstancias que puedan atenuar o agravar la responsabilidad de los delincuentes en un delito dado" (sic). En la sesión 136 y sobre la misma norma: "se acordó agregar en el segundo inciso la palabra ántes, porque tanto importa que el conocimiento de la circunstancia agravante sea anterior como simultáneo con el hecho criminal, i sin esa palabra ántes, se escluiria a los que se hallaren en el primer caso" (sic). Vid. Fernández, Pedro Javier (1899), Código Penal de la República de Chile, Esplicado y Concordado (2. ${ }^{a}$ edición, Santiago, Imprenta, Litografía y Encuadernación Barcelona, 1899), pp.185 y ss.

La norma del Código español rezaba: "Art. 69. Las circunstancias agravantes o atenuantes que consistan en la disposición moral del delincuente, en sus relaciones personales con el ofendido, o en otra causa personal, servirán para agravar o atenuar la responsabilidad de solos aquellos autores, cómplices o encubridores, en quienes concurran".

Las que consistan en la ejecución material del hecho, o en los medios empleados para realizarlo, servirán para agravar o atenuar la responsabilidad únicamente de los que tuvieren conocimiento de ellas en el momento de la acción, o de su cooperación para el delito".

${ }^{23}$ Que consagraba en sus artículos 76 y 77 las reglas sobre comunicabilidad que dan origen remoto a la nuestra. En la primera de ellas se señalaba que: Art. 76. Las circunstancias personales que agraven la pena de un cómplice ó de uno de los autores del crimen, ó que los eximan de responsabilidad, no aprovecharán ni perjudicarán á los restantes. (sic). Asimismo, el artículo siguiente rezaba: Art. 77. Las circunstancias materiales que agravan la pena de un crimen sólo perjudicarán á los autores ó cómplices que tuvieren conocimiento de ellas en el momento de la acción, ó de su cooperación real para el crimen. Vid. Pacheco, Joaquín Francisco, El Código Penal Concordado y Comentado (6. ${ }^{\mathrm{a}}$ edición, corregida y aumentada, Madrid, Imprenta y Fundición de Manuel Tello, 1888), I, p. 398. Con lo reseñado, confirmamos que el mencionado artículo 69 del Código español de 1848 no tiene un correlato en su antecesor, esto es, el Código Penal español de 1822. Sin perjuicio de ello, este último consagraba una norma referida a lo que creemos específicamente tiene relación con la regla de la comunicabilidad de circunstancias personales. Así, su artículo 103 ubicado en el título Preliminar, Capítulo IV, "Del modo de graduar 
La norma se incorpora para resolver la cuestión que deriva de la participación de varios sujetos en un mismo delito en orden a si las circunstancias modificatorias de responsabilidad penal que afectan a uno o más de ellos alcanzan también a los demás. La posibilidad de que circunstancias que concurren en un delincuente pueden transmitirse a los otros que participan en el mismo delito, respecto de la magnitud de pena, se ha llamado la "comunicabilidad de circunstancias atenuantes y agravantes".

La regla — como señala $\operatorname{Novoa}^{24}$ — que se desprende del artículo 64, es que las circunstancias modificatorias personales sirven para atenuar o agravar la responsabilidad de solo aquellos autores, cómplices o encubridores en quienes concurran, sin que se puedan, por tanto, comunicar a otros partícipes. En cambio, las circunstancias objetivas o materiales sirven para atenuar o agravar la responsabilidad de todos los que participaron en el delito, siempre que hayan tenido conocimiento de la misma.

Sobre la aplicación de la norma, parece relevante detenerse en su extensión respecto a otros supuestos de participación. Así, se ha entendido que la misma no solo se referiría a circunstancias atenuantes y agravantes, sino también a circunstancias excluyentes; a las causas de justificación; las de inimputabilidad; inculpabilidad; las excusas legales absolutorias; e incluso a los elementos típicos de un tipo, como lo sería el caso examinado del empleado público en los delitos funcionarios ${ }^{25}$.

Sobre esto último, van Weezel ha señalado que el problema de esta norma no radica solo en la poca claridad de su aplicabilidad respecto de elementos distintos de las circunstancias modificatorias, sino sobre todo en que no proporciona un criterio razonable para distinguir entre distintas clases de delitos especiales ${ }^{26}$. Cabe preguntarse si ese es el rol de la dis-

los delitos y aplicar y dividir las penas (...), a propósito de los reos sentenciados a muerte y a objeto de distinguir cuáles de ellos — de mayor gravedad, como señala su redacción - ingresan al sorteo de la pena capital, señala en su numeral Cuarto: "los que tengan contra sí la circunstancia particular, que no concurra respecto de los demás condenados á muerte..." (sic). Por último y, como sabemos, una de las fuentes relevantes con que contó el Código penal español de 1948 fue el Código Criminal del Imperio del Brasil o Código Criminal do Imperio de 1830, cuyo principal redactor fue VASCONCELOS, código punitivo estudiado principalmente por ZafFaroni y Rivacoba. Vid. Bravo LiRA, Bernardino, La fortuna del Código Penal español de 1848. Historia en cuatro actos y tres continentes: de Mello Freire y Zeiller a V asconcelos y Seijas Lozano, en Anuario de Historia del Derecho Español 74 (2004), pp. 27 y ss. Pese a ello, y como señalamos, la norma del artículo 69 no fue copiada del Código brasileño —el cual no contiene norma alguna sobre esta materia-.

${ }^{24}$ NovoA, Eduardo, cit. (n. 1), pp. 117 y s.

${ }^{25}$ NovOA, Eduardo, cit. (n. 1), pp. 236 y ss.

${ }^{26}$ VAn WeEzel, Alex, El sujeto activo del delito previsto en el art. $97 \mathrm{~N}^{\circ} 4 \mathrm{inc} .2^{\circ}$ del 
posición del artículo 64 o si en realidad la crítica se hace justamente con base en su consideración de principio del Derecho. Aquí se discrepa con dicho autor, tanto en la extensión como en la finalidad que asigna a tal precepto de comunicabilidad.

En primer término, la disposición define su ámbito de aplicación, limitándose expresamente a las "circunstancias atenuantes o agravantes (...)" y no otras, que deben o no comunicarse a los distintos partícipes de un delito ${ }^{27}$.

Asimismo, la norma efectivamente no proporciona criterios para distinguir clases o tipos de delitos especiales, pues la misma en ningún caso está llamada a ese objeto — discusión, si se quiere, de lege ferenda-.

En efecto, se han propuesto algunas soluciones para determinar la punición del extraneus en un delito especial. Una de ellas dice relación con la inclusión de una regla en la Parte General aplicable a todos los delitos especiales que atenúe la pena del partícipe no calificado ${ }^{28}$, y otra, mediante la inclusión de tipos penales específicos que consagren la punibilidad del partícipe extraneus, como es el caso del artículo $250 \mathrm{o}$, el reciente artículo 150 B del Código penal.

En Chile son partidarios de soluciones de este tipo: Balmaceda/Castro $^{29}$ y Grisolía ${ }^{30}$, quienes abogan, siguiendo al modelo alemán ${ }^{31}$, por la consagración de una regla obligatoria para el juez que permita sancionar al extraneus atenuando su responsabilidad respecto al sujeto cualificado.

Código Tributario. Comentario de la sentencia de la Corte Suprema de $1^{\circ}$ de julio de 2008, causa Rol No 638-2008, en Jurisprudencia al día 101 (2008), Año III, p. 1166. [visible en internet: http://www.legalpublishing.cl/LSJ/extras/200811-1/pdfs/JAD_382.pdf]

${ }^{27} \mathrm{Si}$ el legislador no ha querido que se comunicaran las circunstancias agravantes o atenuantes (personales) "no se ve la razón por la cual habría de otorgársela a aquellos que fundamentan la incriminación a un tipo determinado". Vid. CurY, Enrique, cit. (n. 1), p. 232.

${ }^{28}$ Balmaceda, Gustavo - Castro, Carlos, Corrupción y delitos contra la administración pública. Especial referencia a los delitos de malversación de caudales y fraude al Fisco (Santiago, Editorial Librotecnia, 2015), pp. 271 y s.

29 Balmaceda, Gustavo - Castro, Carlos, Corrupción, cit. (n. 28), p. 276.

${ }^{30}$ Grisolía, Francisco (1975), La comunicabilidad en los delitos de malversación y fraude, en Revista de Ciencias Penales 1 (1975), 3a época, T. XXXIV, p. 23.

31 Así, en Alemania el $\ 28.1$ StGB determina una atenuación especial obligatoria para los casos en que en el partícipe no concurran las características personales que fundamenten la punibilidad del autor. El ordenamiento español, por su parte, contempla una solución parecida en el art. 65.3 CP. de 1995 (incorporado por la LO $15 / 2003$ de 25 de noviembre) con atenuación facultativa de la pena al inductor o cooperador necesario en quien no concurran las condiciones, cualidades o relaciones personales que fundamentan la culpabilidad del autor. 
Asimismo, Rodríguez/Ossandón ${ }^{32}$, con base en el modelo español, proponen la inclusión de una regla de atenuación en la Parte General, pero a diferencia de los anteriores, de carácter facultativa para el juez.

Van Weezel ${ }^{33}$ por su parte, al dar cuenta de los problemas que genera la inexistencia en la Parte General de una disposición que regule la punibilidad de los extraneus, se muestra también favorable a la creación de una norma especial que resuelva el problema. Incluso, el Anteproyecto de Código Penal de $2005^{34}$ pretendió, mediante el artículo 45 de su propuesta, consagrar una solución legislativa a este problema. Sobre la archivada propuesta, Ossandón ${ }^{35}$ señala que el precepto contemplado en el anteproyecto supera estas dificultades y adopta una solución de atenuación para el extraneus, similar a la recogida en la legislación comparada.

Como puede apreciarse, las propuestas señaladas nos permitirían sostener, al menos preliminarmente, que la comunicabilidad no podría reconocerse como un principio, pues de serlo permitiría de manera general resolver estos vacíos normativos, como ocurre, v. gr., con el principio del non bis in idem.

Así, y dado los problemas concretos y específicos que se generan a partir de la aplicación de la comunicabilidad, sería necesaria la existencia de nuevas reglas, ya sea en la Parte General o Especial, que determinen desde su concreción y particularidad, la punibilidad del extraneus, sin que sea factible extender más allá de la regulación actual del artículo 64 como principio-, efectos o finalidades que no comprende. Sobre esto, volveremos al final de este trabajo.

${ }^{32}$ Rodríguez Collao, Luis - Ossandón widow, María Magdalena, Delitos contra la función pública. El Derecho penal frente a la corrupción política, administrativa y judicial (Santiago, Editorial Jurídica de Chile, 2005), p. 130.

33 Van WeEzel, Alex, Lesiones y violencia intrafamiliar, en Revista Chilena de Derecho 35 (2008) 2, p. 251, nota 56. En efecto, el autor señala: "En tales casos se requiere una norma que extienda la punibilidad al extraneus, reconociéndole una atenuación de la pena (además de la que le corresponde por no ser el autor del hecho, ya que un extraneus nunca puede infringir el deber institucional). Esta misma norma es la que habría que aplicar para resolver el problema del mayor desvalor de la conducta del extraneus en los delitos especiales impropios: en estas situaciones se produce un concurso aparente de leyes penales, donde prima por especialidad el delito especial, cuya pena podría imponerse atenuada al particular".

34 Secretaría Técnica Comisión Foro Penal, Materiales de Estudio presentados a la Comisión Foro Penal, Parte General, en Politica Criminal 1 (2006) D2, pp. 1-223.

35 De este modo, sea porque se atenúa la pena en relación con el delito especial propio o porque se sanciona en virtud del tipo común paralelo al delito especial impropio, el resultado es que al extraneus siempre se le impondrá una pena menor que al intraneus, solución que se corresponde con el menor injusto que representa su conducta. Vid. Ossandón Widow, María Magdalena, Delitos especiales, cit. (n. 15), p. 3. 
Lo anterior, ha traído como consecuencia que la jurisprudencia mayoritaria afirme sin más la comunicabilidad de las cualificaciones personales en toda clase de delitos, aunque preferentemente en los especiales propios y para "evitar lagunas de punibilidad", pero sin reconocer otra rebaja de la pena para el extraneus que la que se derive de su grado de intervención en el hecho ${ }^{36}$.

Cualquiera sea el caso, se evidencia la limitación del objeto de resolución concreta de la disposición del artículo 64 -y de cualquier precepto que se proponga al efecto- dada la especificidad de su ámbito regulatorio. Lo anterior, pues se trata de una norma que el legislador utiliza sólo para facultar y limitar al juez en el proceso de determinación de la pena aplicable al caso concreto ${ }^{37}$, siempre que concurran los supuestos que ella describe —en palabras de Alexy, por subsunción en ella-, siendo recomendable la creación de nuevas reglas que den solución a aquellos problemas que actualmente escapan de su órbita regulatoria ${ }^{38}$.

Distinta es la discusión respecto de cuáles de las circunstancias modificatorias a que alude el artículo 64 consisten en "la disposición moral del delincuente", "en sus relaciones particulares con el ofendido" o "en otra causa personal", problema que no abordaremos en este trabajo, pero que

${ }^{36}$ VAN WeEzel, Alex, Lesiones, cit. (n. 33), p. 251, nota 56. Relevante aquí resulta recordar — por aplicación del principio de legalidad — que jamás se podrá, bajo pretexto de la existencia de una "laguna de punibilidad", atribuir responsabilidad penal sobre la base de un principio sin que medie una conducta y pena expresamente tipificadas, en este caso, respecto de los extraneus.

${ }^{37}$ En el mismo sentido, Ferdman, Jorge, cit. (n. 13), p. 684. "El artículo 64 tendría aplicación exclusivamente en un ámbito extra típico, una vez que los elementos que contempla esta última categoría hubieren sido fijados ya: el ámbito de la determinación de la pena, específicamente en el de las circunstancias que inciden en su atenuación o incremento".

${ }^{38}$ Las normas llamadas a ejercer una función limitadora del recurso al Derecho penal son los principios, y más en concreto, los que se consideran principios de la Política criminal (Roxin), entendida ésta como el saber que tiene por objeto la acción humana, con el fin de evitar las que son gravemente lesivas para la subsistencia de la sociedad (delitos). En este sentido, el autor reconoce un consenso doctrinal en cuanto a que los principios tienen razón de origen, inicio, punto de partida, o "fuente de las fuentes" del Derecho. Lo anterior, derivaría inevitablemente que, junto a los principios deban surgir reglas, que vendrían a ser otro género de enunciados sin los cuales no sería posible dar respuesta a un conflicto jurídico, operando como correlato conceptual de aquellos. De esta forma, las reglas permiten resolver casos concretos, a los que en cambio no llegarían los principios. Vid. Sánchez-Ostiz, Pablo, Principios y reglas como base para un modelo argumentativo intercultural de Derecho penal, en Cornacchia, Luigi - Sánchez-Ostiz, Pablo, Multiculturalismo y Derecho penal (Pamplona, Thompson Reuters Aranzadi, 2012), p. 42. 
en cualquier caso, responde a una vaguedad legislativa que no faculta al intérprete a extenderse más allá del ámbito jurídico demarcado típicamente, esto es, solo las circunstancias modificatorias, atenuantes y agravantes.

Sobre esto, Rodríguez Collao destaca que hay autores que identifican estas categorías como objetivas o subjetivas, referidas a las circunstancias modificatorias, con las materiales y personales a que alude el Art. 64 ${ }^{39}$. Quizá este esfuerzo de la doctrina por acudir al artículo 64 para resolver otros problemas de extensión de circunstancias distintas de las modificatorias — como las calidades de los sujetos - evidencia justamente que no es principio, pero se intenta recurrir a esta idea para su aplicación.

\section{Posiciones dogmáticas SOBRE LA COMUNiCABILIDAD}

Se reconocen distintas posiciones doctrinarias que han pretendido darle contenido a la comunicabilidad o incomunicabilidad de las calidades especiales que ciertos tipos exigen que concurran en el autor del hecho.

En este sentido, se distinguen tres grandes tesis ${ }^{40}$ : la primera, conocida como la de los comunicantes extremos, fundados principalmente en el denominado principio de indivisibilidad del título de imputación, en virtud de la cual todos los partícipes deben ser sancionados por la misma figura pues se trata de un hecho único que no pude ser considerado jurídicamente de diferente manera para cada uno de los que intervienen conjuntamente ${ }^{41}$.

${ }^{39}$ Esta última distinción, además, nada tiene que ver con los conceptos de objetivo y subjetivo, al menos no en el sentido en que estos generalmente son utilizados en el ámbito de las ciencias penales, es decir, en referencia a elementos que se dan en el mundo exterior o en la mente de una persona, respectivamente. Vid. RodríGuez Collao, Luis, Los principios rectores del Derecho Penaly su proyección en el campo de las circunstancias modificatorias de responsabilidad criminal, en Revista de Derechos Fundamentales (Universidad Viña del Mar) 8 (2012), p. 163.

${ }^{40}$ Una detallada revisión de la dogmática en torno a la comunicabilidad, en BALMACEDA, Gustavo, Comunicabilidad de la calidad del sujeto activo en los delitos contra la función pública: especial referencia a la malversación de caudales públicos y al fraude al fisco, en RDUCN 19 (2012) 2, pp. 45 - 81. Con modificaciones mínimas, también en BALMACEDA, Gustavo - Castro, Carlos, Corrupción, cit. (n. 28), pp. 233 y ss.

${ }^{41}$ Cuyo principal expositor en Chile ha sido Novoa, Eduardo, Curso de Derecho Penal Chileno (Santiago, Editorial Jurídica de Chile, 2005), II, pp. 207 y ss. Se fundamentan también en el principio de accesoriedad, esto es, que el partícipe accede a la conducta del intraneus (arts. 51 y ss. del CP.); en la ausencia de norma positiva expresa sobre la comunicabilidad de elementos integrantes del tipo penal (art. 64), por lo cual éstos debiesen poder ser comunicados; en la solidaridad psicológica con el autor; en la imputación según el propio dolo, o conocimiento del delito que ha de cometerse y; la finalidad de la ley cual es la protección de bienes jurídicos, indistintamente de si se 
Una de las principales críticas que se plantea a esta tesis tiene su fuente en el mismo principio de indivisibilidad del título al que se recurre para sustentarla, pues de existir varios ejecutores materiales, no queda más remedio que admitir la divisibilidad del título de imputación, en tanto no existe fundamento para que uno de ellos reclame preeminencia sobre el otro para determinar el título del delito, ni para que haya de ser precisamente el intraneus quien decida el título del delito ejecutado por todos ${ }^{42}$.

Una segunda tesis, denominada como la de los incomunicantes limitados ${ }^{43}$, la cual distingue casos de incomunicabilidad, principalmente

tiene o no la calidad especial exigida por el tipo. Sobre estas posturas y en particular, sobre el concepto de empleado público, véase Ossandón Widow, María Magdalena, Sobre la calidad de empleado público en los delitos funcionarios, en Revista Doctrina y Jurisprudencia Penal 8 (2012), Año 3, pp. 62 y ss. Se suma a esta interpretación, GARrido MontT, Mario, Etapas de ejecución del delito. Autoría y participación (Santiago, Editorial Jurídica de Chile, 1984), p. 236: "El principio de la accesoriedad, como ser, es sólo aplicable al caso de varias acciones independientes que se complementan, pero no así en las hipótesis de una sola acción con sujeto plural. Otro tanto sucede con los delitos denominados especiales, donde el tipo penal exige al autor una cualidad particular (ser funcionario, padre, casado), pero en los que no rechaza la posibilidad de que sean cometidos mediante una acción única realizada por varios sujetos, entre ellos extraneus. En esta alternativa, por tratarse de una sola acción con sujeto múltiple, le corresponderá también una calificación jurídica única, que afectará por igual a todos los intervinientes".

${ }^{42}$ Cury, Enrique, Derecho Penal. Parte General (8. ${ }^{a}$ ed., Santiago, Ediciones Universidad Católica de Chile, 2005), p. 644. El mismo autor complementa señalando que la idea de que la calificación del delito esté dada por el autor — defendida por SCHEPELER-, no resuelve los casos en que concurran al hecho dos o más coautores, siendo solo uno de ellos intraneus. Así, no existiría razón para que sea precisamente la actuación de tal sujeto la que decida el título del delito cometido por todos. En realidad, considera, la tipicidad es siempre determinada, fundamentalmente, por la naturaleza de la acción, de la cual las cualidades personales especiales que concurren en el sujeto activo no son más que una modalidad accesoria. Finalmente, y como fundamento de lege data, postula que, respecto a que un mismo hecho no puede ser calificado en forma distinta para las diferentes personas que intervienen en él, ello no es correcto, pues es precisamente lo que ocurre en los supuestos de concurso ideal de delitos, reconocido de manera expresa en el artículo 75 del CP. chileno. Vid. Cury, Enrique, cit. (n. 1), pp. 229 y ss.

${ }^{43}$ Con matices, abogan en Chile por esta tesis, entre otros, Etcheberry, Alfredo, cit. (n. 1), pp. 81 y ss.; Politoff, Sergio - Grisolía, Francisco - Bustos, Juan, Derecho Penal chileno. Parte especial. Delitos contra el individuo en sus condiciones físicas (2. ${ }^{\mathrm{a}}$ edición, Santiago, Editorial Jurídica de Chile, 2006), pp. 140 y ss.; Bullemore, Vivian - Mackinnon, John, Curso de Derecho Penal. Parte Especial (Segunda Edición, Santiago, Editorial LexisNexis, 2007, Chile), IV, pp. 35 y ss.; Politoff, Sergio - Matus, Jean Pierre - Ramírez, Maria, Lecciones de Derecho Penal chileno. Parte General (2. ${ }^{a}$ edición, Santiago, Editorial Jurídica de Chile, 2004), pp. 423 y ss.; VArgas, Tatiana, Manual de 
por la separación entre delitos especiales propios e impropios. En los delitos especiales propios el tipo penal designa como autor a sujetos que poseen una calidad especial, sin que se contemple un tipo penal aplicable a los sujetos que no la posean, como es el caso del delito de prevaricación. En estos casos, se comunica la calidad especial exigida en el tipo pues no existe una figura residual aplicable al extraneus, evitándose así lagunas de punibilidad.

En cambio, son delitos especiales impropios, aquellos que pueden ser cometidos por cualquiera, pero en los cuales la calidad especial del sujeto agrava la penalidad, existiendo un tipo base o residual aplicable a los que no la posean, como sería el caso del delito de fraude al Fisco en relación al de estafa. En estos casos y en aplicación del artículo 64, la calidad especial no se comunica al extraneus, quien responde por el tipo residual que fuere aplicable.

A nuestro juicio, uno de los mayores problemas que presenta esta tesis radica en que funda la imputación del extraneus dentro los delitos especiales propios, en la evitación de su impunidad ${ }^{44}$, dado a que no existe figura residual o subyacente que le sea aplicable — laguna de punibilidad-, sancionado al intraneus y extraneus bajo el mismo parámetro sólo por razones de justicia material, poniendo en jaque el principio de legalidad ${ }^{45}$. Asimismo, no da soluciones claras respecto al título de imputación por el cual sancionar al extraneus, barajándose hipótesis de lege ferenda para su punición, de acuerdo a lo expuesto supra.

Finalmente se encuentran los denominados incomunicantes extre-

Derecho Penal Práctico. Teoría del Delito con Casos (Segunda Edición, Santiago, Editorial Legal Publishing-Thomson Reuters, 2011, Chile), pp. 280 y ss.; GAETE, Sergio, La comunicabilidad en torno a los elementos del delito, Memoria $\mathrm{N}^{\circ} 7$ (Santiago, Editorial Jurídica de Chile, 1963), 62 pp.; Ferdman, Jorge, cit. (n. 13), pp. 683, para quien más que un problema de comunicabilidad, se trata de un problema de tipicidad: "de no concurrir el autor calificado, resultará que no sólo estaremos en presencia de un problema de autoría o de participación, sino que nos enfrentamos a un elemento al cual se subordina la existencia misma del injusto". Lo anterior, pese a que accedería a comunicar la calidad especial si en los hechos el sujeto asume una posición de garante o reside en él el dominio del hecho.

${ }^{44}$ En el mismo sentido: Ferdman, Jorge, cit. (n. 13), pp. 682 y 683. Quien agrega que tal razonamiento más bien parece el resultado del temor que la impunidad de los denominados extraneus pudiere conllevar. Pero esta crítica, agrega, no puede sin más autorizar soluciones que en lo sustancial se alejan y desconocen el cometido asociado al tipo penal, ni autorizan o legitiman la comunicabilidad, derechamente "incurso en la analogía".

${ }^{45}$ Sobre esta y otras críticas, Ossandón Widow, María Magdalena, Sobre la calidad, cit. (n. 41), pp. 64 y ss., quien agrega que podría existir una verdadera in co herencia valorativa en el ejercicio propuesto. 
mos, tesis en virtud de la cual cada partícipe debe ser castigado según la naturaleza del injusto que cometen, por lo que nunca procede extender el injusto de otro. La tesis se apoya, además, en la interpretación sistemática de la ley: si el legislador no ha querido que se comunicaran las circunstancias agravantes o atenuantes (art. 64 inc. $1^{\circ}$ CP.), "no se ve la razón por la cual habría de otorgársela a aquellos que fundamentan la incriminación a un tipo determinado" ${ }^{46}$.

Asimismo, se apoyan en el principio de legalidad; consideraciones teleológicas sobre la naturaleza del injusto; arbitrariedad y volatilidad de la distinción entre delitos especiales propios e impropios; existencia de tipos penales que consagran expresamente la responsabilidad del extraneus en delitos especiales propios; e inidoneidad de las penas ${ }^{47}$. Su principal crítica, como ya se ha señalado, radica en que impediría la punibilidad del partícipe extraneus en delitos especiales propios, permitiendo su impunidad ${ }^{48}$.

Actualmente, pareciera tener mayor sustento y desarrollo dogmático la denominada incomunicabilidad limitada, pero recurriéndose a los denominados delitos de infracción de deber o Pfichtdelikten, categoría propuesta por Roxin ${ }^{49}$, quien a partir de ciertas constelaciones problemáticas, como los supuestos de "instrumento doloso no cualificado", en que la teoría del dominio del hecho se muestra como insuficiente y puede llevar a la impunidad, tanto del sujeto de adelante como el de atrás, plantea la teoría de la infracción de deber, en que es autor aquel que infringe un deber jurídico especial y extrajurídico, como sucede en los delitos especiales.

Esta tesis tampoco ha estado exenta de críticas. Una de ellas fundada en que, a partir de su formulación se ha llevado a una concepción dual

46 Así, especialmente: Cury, Enrique, cit. (n. 1), pp. 229 y ss.

47 Véase, Ossandón Widow, María Magdalena, Sobre la calidad, cit. (n. 41), pp. $68-71$.

48 Razón principal por la que Cury, Enrique, cit. (n. 42), p. 647, finalmente, abandona esta posición.

49 Vid. Roxin, Claus, Autoría y dominio del hecho en Derecho penal (traducción de

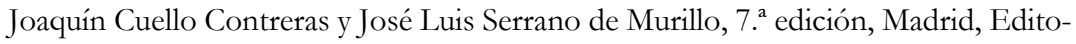
rial Marcial Pons, 1999), pp. 352 y ss. Para un desarrollo del origen y función de los delitos de infracción de deber, véase Ossandón Widow, María Magdalena, Delitos especiales, cit. (n. 15), pp. 1 - 22. Sin perjuicio de ello, la postura de Roxin no está exenta de críticas. Gómez Martín reconoce algunas de ellas y, entre otras, critica que la construcción de Roxin estaría incompleta, pues la misma requiere previamente una categorización en la parte especial de aquellos delitos en que efectivamente existirían estos deberes jurídicos especiales y extrapenales (Pfichtdelikten), tarea aún pendiente. Vid. Gómez Martín, Víctor, Delitos de posición y delitos con elementos de autoría meramente tipificadores: una distinción necesaria para los delitos especiales de funcionario, en Revista Doctrina y Jurisprudencia Penal 8 (2012), Año 3, pp. 3-44. 
y no unitaria de autor — uno vinculado al dominio del hecho y otro al de infracción de un deber especial — no siendo aplicable a toda clase de delitos. Asimismo, se ha criticado la necesidad de la tesis de recurrir a criterios que permitan concretar cuáles son aquellos tipos en los que el legislador limita el círculo de autores bajo la exigencia de un deber jurídico extrapenal, siendo así una construcción incompleta ${ }^{50}$.

Sin perjuicio de esto, Hernánde $z^{51}$ ha señalado que esta tesis, creciente en la literatura, permite que, en tanto no exista norma expresa al respecto, las calidades personales nunca se pueden comunicar al extraneus, quien solo puede responder, tratándose de los delitos especiales impropios, por el delito común que le sea aplicable, debiendo quedar impune en caso de no existir la figura residual, que es precisamente lo que pasa con los delitos especiales propios.

La aseveración es compatible con lo que aquí hemos defendido en cuanto a que, no concurriendo la comunicabilidad de elementos integrantes del tipo en la descripción normativa del artículo 64, ella sólo debiese surtir sus efectos en aquellos ámbitos que le son propios. No ocurriría así si se tratase de un principio, pues la norma está sujeta a la mayor o menor extensión que el legislador le entregue típicamente y sobre ello, y solo en ello, tendrá validez.

Por lo mismo, cobran especial sentido las palabras de van Weezel cuando señala que: "De esta manera, la comunicabilidad queda entregada al albur de las diferentes técnicas legislativas en cada ámbito del derecho penal" ${ }^{2}$. La declaración no procede si se tratara de un principio.

La mayor o menor extensión de la disposición del artículo 64, ya sea si contempla la comunicabilidad de circunstancias eximentes de responsabilidad penal, las causas de justificación, causales de inimputabilidad o exculpación, o incluso elementos del tipo penal, responde netamente a su concreción normativa, mas no al arbitrio jurisdiccional como se ha expuesto en este trabajo.

IV. Concepto y aplicación de los principios del Derecho, en especial en el Derecho penal

Los principios generales del Derecho fundamentan y dan cimiento a la

${ }^{50}$ Véase Gómez Martín, Víctor, cit. (n. 49), pp. 15 y ss.

${ }^{51}$ En Hernández Basualto, Héctor, Comentario al artículo 14, en Couso Salas, Jaime - Hernández Basualto, Héctor (directores), Código Penal comentado. Parte General Doctrina y jurisprudencia (Santiago, AbeledoPerrot-LegalPublishing, 2011, Chile), pp. 377 y ss.

${ }^{52}$ VAn WeEZel, Alex, El sujeto activo, cit. (n. 26), p. 1166. 
ley, iluminan su contenido, integran sus vacíos, trazan sus límites y sirven de guía tanto al jurista como al juez para su aplicación al caso concreto. De allí que los mismos no requieran ser reconocidos ni tipificados en el ordenamiento jurídico positivo ${ }^{53}$, circunstancia que de ocurrir no afectaría su carácter de principios ${ }^{54}$. Son, por tanto, anteriores a los designios

53 Sin perjuicio de lo señalado, los principios han tenido expresa acogida en la codificación. Como destaca Esser, es frecuente que el legislador haga remisión a los principios jurídicos generales, a los fundamentos naturales de derecho olos principios que se desprenden del espíritu del ordenamiento ( $\$$ ABGB, artículo 15 Código Albertino, artículo 3 del Código civil italiano, artículo 6 del Código civil español, cf. además $\ 1$ del Primer Proyecto del BGB y artículo 1 I ZGB). Asimismo, a la razón y a la equidad (art. 3 del Código japonés), o sólo a la equidad (arts. 565, 1135 y 1854 del Código civil francés). La práctica, explica el autor, tiene su origen en la necesidad de dar integridad al ordenamiento jurídico de manera de completar aquellas lagunas normativas, ejercicio propio del positivismo jurídico. Vid. Esser, Joseph, Principio y norma en la elaboración jurisprudencial del derecho privado (trad. Eduardo Valentón Fiol, Bosch, Barcelona, 1961), p. 191. En el mismo sentido, Henríquez, agregando el caso del Código Civil uruguayo de 1889, ex artículo $1^{\circ}$, y como trataremos más adelante, en nuestro Código Civil al referirse en su artículo 24 al espíritu general de la legislación. Henríquez, Ian, La regla de la ventaja para el concebido en el Derecho Civil chileno (Santiago, Editorial Legal Publishing, 2011), p. 22.

${ }^{54}$ Específicamente se pronuncia Sánchez-Ostiz, para quien no se hallarían siempre positivizados, aunque su plasmación legal o jurisprudencial coopera a la obtención de consenso y aplicación. Vid. Sánchez-Ostiz, Pablo, cit. (n. 38), p. 46. En el mismo sentido, Esser, quien señala que los principios estructurales y constructivos no funcionan en virtud de su mención oficial, sino en virtud de la manipulación real de un ordenamiento. Esser, Joseph, cit. (n. 53), p. 190. Para otros, la positivización no corresponde al legislador, cuya finalidad es la de crear normas y no principios, precisamente por la quimera tarea de tipificarlos y, por tanto, restringirlos, atentando contra su propia naturaleza de generalidad y abstracción. Así, la consagración de los principios correspondería a la doctrina y jurisprudencia, que los reconocen mediante un método depurado tras su plasmación histórica. Su positivización implicaría su desnaturalización, convirtiéndolos en reglas, pues necesariamente se verán limitados atendida su mayor o menor descripción normativa. Vid. Vergara Blanco, Alejandro, Los principios jurídicos y la tarea de construir el derecho administrativo en clave cientifica, en Revista de Derecho Administrativo 6 (2012), pp. 68 y s. Por su parte, YACOBUCCI, Guillermo, El sentido de los principios penales (Buenos Aires, Editorial BdeF, Argentina, 2014), p. 101, señala que los principios configuradores o materiales del Derecho penal tienen una juridicidad y "positividad" de algún modo "natural", en tanto se les reconoce su emergencia primaria a partir de la racionalidad humana, sus vínculos, fines, bienes y valores, especialmente los que surgen de la convivencia social. En nuestro tiempo, incluso, parte de esa evidencia o naturalidad se proyecta a los principios que han sido mayoritariamente reconocidos como fundamentales por el ordenamiento constitucional. Para un desarrollo más acabado y una teoría general de 
cambiantes del legislador ${ }^{55}$.

En nuestra opinión, una de las principales funciones de los principios dice relación con iluminar e interpretar, desde su abstracción, aspectos generales del ordenamiento jurídico, lo cual no sería posible desprender de las reglas. Como veremos, ellas están llamadas a resolver problemas concretos, sin que proceda una aplicación extensiva más allá de sus marcos descriptivos.

Los principios constituyen así la base valórica o espíritu del orden jurídico, otorgando coherencia axiológica a su funcionamiento. En materia penal, se les reconoce como fuente de la potestad sancionadora estatal y, por tanto, parámetros para su interpretación. En efecto, Yacobucci los sitúa como las causas que motivan, producen, explican y justifican la presencia del ius puniendi en la convivencia política. Es decir, la fuente real u ontológica de la que surge la realidad llamada Derecho penal ${ }^{56}$.

Por su parte y, entregando criterios para su definición, Sánchez-Ostiz los considera como “(...) enunciados normativos con pretensiones de validez y aplicación, caracterizados por ser origen de otras decisiones jurídicas, a las que dan sentido, y por estar dotados de elevado grado de abstracción (...)" 57 .

Los principios generales del Derecho se traducen así, en la amalgama que permite dar coherencia al conjunto de normas que conforman el ordenamiento jurídico y, como veremos, constituyen los elementos integradores del sistema a partir de su función eminentemente hermenéutica ${ }^{58}$.

los principios jurídico-penales, véase: Sánchez-Ostiz, Pablo, Fundamentos de Política Criminal. Un retorno a los principios (Madrid, Marcial Pons, 2012).

55 Alcalde, Enrique, Los principios generales del Derecho (Santiago, Ediciones Universidad Católica de Chile, 2003), pp. 60 y s., quien divide los principios generales del Derecho entre los emanados de la propia naturaleza humana y los institucionales, señala que “(...) aquellos que integran el primer grupo se erigen en garantía de la persona, impidiendo que sea desconocido, aún por el legislador, aquello que — como a cualquier otra creatura-le es más propio: su naturaleza y todo lo que de ella emana". Así, señala Alexy, hay quienes distinguen los conceptos de principio y de norma, en que la segunda tiene un marco definido que deslinda su aplicación, aquel, en cambio, al carecer de una descripción precisa del hecho típico destinado a regular, podría decirse que en sí mismo lleva envuelta su indeterminación, o lo que nosotros aquí preferimos llamar como su gen eralidad. Sin perjuicio de lo anterior, Alexy señala que tanto las leyes —o reglas - como los principios, son tipos de normas, pues se expresan a través de mandatos, permisiones y prohibiciones, si por norma entendemos simplemente una enunciación deóntica — de deber ser-. Alexy, Robert, Teoría de los derechos, cit. (n. 11), p. 83.

${ }^{56}$ Yacobucci, Guillermo, cit. (n. 54), p. 79.

57 SÁnchez-Ostiz, Pablo, cit. (n. 38), p. 18.

${ }^{58}$ Sin perjuicio de lo cual no sería su única función. Esser, al tratar sobre la natu- 
Dicha función, como es sabido, emana directamente de la Constitución y la ley, en cuanto a la proscripción recaída en el juez de excusarse de la resolución de una contienda jurídica, aun cuando no exista disposición legal llamada a resolverla o mandato de inexcusabilidad ${ }^{59}$.

En efecto, y ante la imposibilidad de prever y regular todos los casos, el mismo legislador ha señalado las fuentes a las cuales el juez debe acudir siempre que no sea posible resolver una controversia aplicando una disposición precisa de la ley ${ }^{60}$. De allí la necesidad de recurrir a los principios.

Estas fórmulas, provienen del Código civil Albertino y del austriaco. Este último indica en su $\int 7 .^{\circ}$ que “(...) cuando el caso permanezca aún dudoso, deberá decidirse según los principios del Derecho natural, teniendo en cuenta todas las circunstancias del mismo, cuidadosamente consideradas y pesadas" (bis) ${ }^{61}$.

$\mathrm{El}$ origen de esta forma de entender la ley, y que extendemos al fin mismo de los principios del Derecho, sería aún anterior. Ya Aristóteles comprendía, por su generalidad y abstracción, o como él señala, por su universalidad, que la ley muchas veces es insuficiente para resolver casos concretos y que la misma requería una corrección a través del recurso a la equidad, o lo que él denominaba como epieikeia ${ }^{62}$.

raleza jurídica y fines de los principios pone de relieve la importancia de ellos como fuentes del Derecho, para la creación jurisprudencial y para el descubrimiento del Derecho en general, reconociendo las complejidades de su clasificación y definición en su "intento" por lograrlo. Véase, Esser, Joseph, cit. (n. 53), p. 438.

${ }^{59}$ Así, y de acuerdo con el inciso segundo del artículo 76 de nuestra Carta Fundamental, reclamada su intervención en forma legal y en negocios de su competencia, los jueces no podrán excusarse de ejercer su autoridad, ni aun por falta de ley que resuelva la contienda o asunto sometidos a su decisión. Dicha norma es, a su vez, replicada literalmente en el artículo 10 de nuestro Código Orgánico de Tribunales.

${ }^{60}$ En el mismo sentido, Del Vecchio, Georgio, Los principios generales del Derecho (Lima, Ara Editores, 2006), p. 36. En nuestro país, dicha regulación es acogida en el ordenamiento jurídico, específicamente al tratar sobre la interpretación de la ley en el Libro I del Código Civil, el cual en su artículo 24 reza que, en los casos a que no pudieren aplicarse las reglas de interpretación precedentes, se interpretarán los pasajes obscuros o contradictorios del modo que más conforme parezca al espíritu general de la legislación y a la equidad natural. Otro tanto hace el legislador, al consagrar los requisitos de las sentencias definitivas, en especial el artículo 170 del Código de Procedimiento Civil, el cual en su numeral $5^{\circ}$ señala expresamente que, en defecto de la ley, la sentencia deberá fundarse en los principios de equidad con arreglo a los cuales se pronuncia el fallo.

${ }^{61}$ Del Vecchio, Georgio, cit. (n. 60), p. 38. Por su parte, el Código Albertino se refirió específicamente a los principios generales del Derecho en su artículo 15, señalando que “( ...) cuando al caso permanezca aún dudoso, deberá decidirse según los principios generales del Derecho, tomando en consideración todas las circunstancias del caso".

${ }^{62}$ La causa de ello, señala Aristóteles, “(...) es que toda ley es universal y que 
Pese a lo señalado, pareciera ser que existen importantes matices a la hora de aplicar estos criterios hermenéuticos — generales o comunes - al Derecho penal, dada la naturaleza de última ratio de esta área, que obligan a limitar ciertos criterios de interpretación ${ }^{63}$. En otras palabras, el mandato de inexcusabilidad opera con mayor rigidez en materia penal, en cuanto a que, a falta de ley que sancione una conducta, no puede atribuirse respon-

hay casos en los que no es posible tratar las cosas rectamente de un modo universal. En aquellos casos, pues, en los que es necesario hablar de un modo universal, sin ser posible hacerlo rectamente, la ley acepta lo más corriente, sin ignorar que hay algún error. Y no es por eso menos correcta, porque el yerro no radica en la ley, ni en el legislador, sino en la naturaleza de la cosa, pues tal es la índole de las cosas prácticas. Por tanto, cuando la ley presenta un caso universal y sobrevienen circunstancias que quedan fuera de la fórmula universal, entonces está bien, en la medida en que el legislador omite y yerra al simplificar, el que se corrija esta omisión, pues el mismo legislador habría hecho esta corrección si hubiera estado presente y habría legislado así si lo hubiera conocido. Por eso, lo equitativo es justo y mejor que cierta clase de justicia, no que la justicia absoluta, pero sí mejor que el error que surge de su carácter absoluto. Y tal es la naturaleza de lo equitativo: una corrección de la ley en la medida en que su universalidad la deja incompleta." Aristóteles, Ética Nicomaquea (Madrid, Gredos, 2000), 1137b 10-20. En el mismo sentido, Gadamer, Hans-Georg, Verdad y Método I (11. a edición, Salamanca, Ediciones Sígueme, 2005), p. 389 y ss., "Aristóteles muestra que toda ley se encuentra en una tensión necesaria respecto a la concreción del actuar, porque es general y no puede contener en sí la realidad práctica en toda su concreción”. Haciendo concesiones frente a la ley se encuentra un Derecho mejor, concluye el autor. Así, la aplicación de la ley sin considerar el caso concreto sería injusta.

${ }^{63}$ Antiguos principios del Derecho Romano expresados en la fórmula in dubio pro reo -Digesto, lib. 48 - y que han influido en algunas disposiciones legales, como el artículo 18 del Código Penal que ordena juzgar al reo conforme a una ley posterior al hecho, siempre que ésta exima el hecho de toda pena o le aplique una menos rigurosa) y el artículo 74 del Código Orgánico de Tribunales — previo a la modificación hecha por la Ley N. ${ }^{\circ} 19.708$ de 2001 - establecía que si en un tribunal colegiado la mitad de los votos se uniforma a favor del reo bien sea para absolverlo, bien sea para aplicarle pena menor, esta opinión formará sentencia, han hecho pensar que las leyes penales deben ser interpretadas siempre en sentido favorable al reo. Para ello se ha argumentado que los preceptos de carácter penal deben ser interpretados de manera restrictiva, poenalia sunt restringenda, por el rigor contenido en éstos y por la limitación o restricción de la libertad individual que imponen, de manera que si hay dos o más interpretaciones posibles, debe elegirse aquélla que resulte más benigna para el reo. NovoA, Eduardo, cit. (n. 1), pp. 140 y s. En el mismo sentido, las reglas sobre la analogía también adquieren una significación propia en el Derecho Penal, al proscribirse la denominada analogía in malam partem. Así, cuando el juez establezca el sentido de las normas para determinar qué supuestos se encuentran recogidos por éstas, no puede desbordar los límites de los términos de la ley y aplicarla a supuestos no previstos en la misma. De esta manera, el tenor literal se convierte en un límite a la interpretación de la ley penal. Vid. Rodríguez Collao, Luis, cit. (n. 39), p. 156. 
sabilidad fundando ésta en el espíritu general de la legislación o los principios del Derecho (lo que pareciera hacer la Corte Suprema en el fallo aquí comentado). Salvada esta excepción, el recurso a los principios en Derecho penal seguiría la misma suerte que en materia civil.

Así, y desde el prisma penal, Yacobucci distingue tres categorías de principios: fundamentales, derivados y estándares ${ }^{64}$. Los principios fundamentales, dada su relevancia y consistencia en la configuración del sistema penal, son los de culpabilidad y legalidad ${ }^{65}$. A estos le seguirían los principios derivados, en tanto son una consecuencia axiológica de aquellos - dentro los cuales comprende los de proporcionalidad, última ratio y o fensividad-. A los ya señalados añade los estándares, cuya naturaleza es diversa de la de los principios, pero igual de relevantes pues juegan un rol fundamental en la instancia de aplicación de los principios, es decir, en el caso concreto. Así, son entendidos como niveles de la razonabilidad exigida en la aplicación concreta de normas o conceptos iuspositivo $\mathrm{s}^{66}$. Como veremos, pareciera que la comunicabilidad no respondería a la categoría de principios del Derecho, ya sean fundamentales o derivados, sino más bien al de una regla.

\section{Análisis crítico de la comunicabilidad como principio en el Derecho penal}

Como ya se dijo, los principios del Derecho penal se caracterizan,

${ }^{64}$ Yacobucci, Guillermo, cit. (n. 54), p. 95. Con otra visión y clasificación, consultar a Baratta, Alessandro, Principios de Derecho Penal mínimo. Para una teoría de los Derechos Humanos como objeto y límite de la ley penal, en Doctrina Penal. Teoría y Práctica en las Ciencias Penales 87 (2003), Año 10, pp. 623-650. Distingue entre principios intrasistémicos y extrasistémicos. En los primeros incorpora los principios de limitación formal, funcional, personal o de limitación de responsabilidad penal; y en los segundos, los de descriminalización, metodológicos de construcción alternativa de conflictos y de problemas sociales. Asimismo, desarrolla en cada uno de ellos los que entre nosotros se denominarían como principios clásicos: culpabilidad, legalidad, última ratio, etc.

${ }^{65}$ En esta afirmación no existen voces disonantes, pues los mismos se han erigido como pilares fundacionales del Derecho penal y, tanto en la teoría como en la práctica, existe un difundido consenso respecto de las consecuencias que se derivan del principio de legalidad. En particular se reconocen cuatro prohibiciones derivadas de este último: el de aplicación retroactiva de la ley (lex praevia); de aplicación de otro derecho que no sea el escrito (lex scripta); de extensión del derecho escrito a situaciones análogas (lex stricta); de cláusulas legales indeterminadas (lex certa). Vid. Bacigalupo, Enrique, Principios Constitucionales de Derecho Penal (Buenos Aires, Hammurabi, 1999), pp. 44 y 45.

${ }^{66}$ Yacobucci, Guillermo, cit. (n. 54), p. 125. 
entre otras cualidades, por constituir fuentes del Derecho y, asimismo, parámetros hermenéuticos frente a vacíos y lagunas legales ${ }^{67}$, función que difiere del resto de los principios que componen el ordenamiento jurídico, por estar sometidos a límites específicos de esta rama punitiva, como el in dubio pro reo; prohibición de la analogía in malam partem y permisión de la in bonam partem; fragmentariedad; admisión del error de Derecho en ciertas hipótesis; non bis in idem; presunción de inocencia; entre otros ${ }^{68}$.

Sin embargo, la literatura ha reconocido otras categorías jurídicas que no reunirían las características propias de los principios del Derecho, como el ser fundacionales, informadores, integradores, generales, o indeterminados por su abstracción. Así, no son pocos los trabajos que se han afanado en el estudio de los denominados a forismos, máximas, estándares y, en lo que aquí nos interesa, las denominadas reglas o normas jurídicas, que en ocasiones se confunden con los principios ${ }^{69}$.

${ }^{67}$ Sobre el sentido de los principios penales, y a nuestro juicio, igualmente de los principios generales del Derecho, señala YACOBUCCI, Guillermo, cit. (n. 54) p. 97, que, por un lado, "constituyen reglas de configuración o fundamentadoras del sistema; por otro, serían fuente de interpretación e integración de carácter normativo, con un especial contenido axiológico, pues se ordenan a la realización de ciertos bienes". De allí entonces, “(...) sus funciones fundamentadoras, integradoras y legitimantes, que se reflejan primordialmente en el ámbito de aplicación e interpretación de la ley”.

${ }^{68}$ En cuanto a la aplicación de estos principios penales, ZafFaroni, Raúl (1987), Tratado de Derecho Penal (Buenos Aires, Ediar, 1987), I, p. 124, aclaraba que una cosa es tener en cuenta los principios generales del Derecho a la hora de interpretar la ley, y otra distinta es pretender pasar sobre el principio de legalidad llevando como estandarte esos principios. En el primer sentido, los principios tienen plena vigencia para el Derecho penal. En el segundo de los criterios, estos principios no pueden esgrimirse de manera contraria al principio de legalidad, puesto que éste es, precisamente, una clara derivación de los mismos principios generales de nuestro Derecho penal. Sobre esto, no podemos dejar de plantearnos el carácter, siguiendo a Maturana- a utopoiético de nuestra ciencia, la cual se genera y auto regula, al menos desde su concepción moderna, a sí misma, siendo su principio paradigmático el de legalidad a partir de cual surgen nuevos principios — secundarios o derivados- los cuales deben ceñirse al de su origen, así como su intangibilidad respecto de otros principios, también de carácter general del Derecho. En esta lógica, es inevitable concluir que, no sólo los principios, sino las reglas o normas penales, como categorías jurídicas, también deben ceñirse a aquel. Maturana, Humberto - Varela, Francisco - URIBE, Roberto, Autopoiesis: The organization of living systems, its characterization and a model, en Biosystems 5 (1974) 4, pp. 187-196.

${ }^{69}$ Entre otros, y desde la teoría de la ley, ver García Amado, Juan Antonio, Principios, reglas y otros misteriosos pobladores del mundo jurídico. Un análisis (parcial) de la Teoría de los derechos fundamentales de Robert Alexy, en Carbonell, Flavia - Coloma, Rodrigo - Letelier, Raúl (coordinadores), Principios Jurídicos, análisis y crítica (Santiago, Thompson Reuters, 2011, Chile), pp. 29-64; CArboneld, Flavia - Letelier, Raúl, cit. 
En este sentido, compartimos con Squella, y desde el punto de vista de su fundamentalidad, que son características propias de los principios y que los distinguen de las reglas o normas, su mayor abstracción, mayor generalidad y concisión ${ }^{70}$. Tendrían así una anatomía distinta a la de las reglas y, ergo, funciones diversas. Por ello, se han elaborado ciertos criterios para distinguir los principios de las reglas.

Un primer criterio lo encontramos en el contenido de los principios, que serían los fines y valores últimos de las reglas y su justificación ${ }^{71}$. Un segundo estándar descansaría en su generalidad o amplitud, pues los principios tendrían una extensión comprensiva del sistema en su totalidad, en cambio las reglas o normas se limitarían a resolver casos concretos ${ }^{72}$. Un tercer criterio se fundaría en la validez, la que según Dworkin, para el caso de los principios, permite observar colisiones de dos o más principios frente a un mismo conflicto jurídico, sin que ello signifique la invalidez o exclusión de alguno de estos para resolver el caso concreto — aplicables en mayor o menor medida incluso de manera paralela—; mientras que las reglas serán aplicables in an all-or-notbing fashion (sic), es decir, en razón de "todo o nada", excluyentes unas de otras para dar solución al caso específico ${ }^{73}$.

Finalmente, se distinguen en cuanto a que la validez de los principios no descansa en su determinación normativa, la que como ya señalamos

(n. 7), pp. 155-184; Vergara Blanco, Alejandro, Delimitary distinguir: teoría del derecho, filosofía del derecho y doctrina jurídica, en Revista de Derecho de la Pontificia Universidad Católica de Valparaíso 44 (2015), pp. 623-660; Vergara Blanco, Alejandro, Los principios, cit. (n. 54), pp. 63-80; HenríQuez, Ian, cit. (n. 53); Alcalde, Enrique, cit. (n. 55).

${ }^{70}$ SQuella, Agustín, cit. (n. 6), p. 24.

${ }^{71}$ Como destaca Esser, Joseph, cit. (n. 53), p. 252, "Los principios son el punto de partida del razonamiento jurídico: no como simples instrumentos de pensamiento heurístico (aumento del conocimiento), sino como expresión primaria de una decisión valorativa de carácter positivo, que es la que confiere su legitimación a la regla que debe ser aplicada".

72 Así, entre otros: Alexy, Robert, Teoría de los derechos, cit. (n. 11), p. 83; Vergara Blanco, Alejandro, Los principios, cit. (n. 54), pp. 68 y s.; Esser, Joseph, cit. (n. 53), p. 248; Rodríguez, Pablo, Teoría de la Interpretación Jurídica (Santiago, Editorial Jurídica de Chile, 2004), pp. 84 y 85; Sánchez-Ostiz, Pablo, cit. (n. 38), p. 18; SQuelLa, Agustín, cit. (n. 6), p. 24. Por su parte, y desde una posición más radical, García Amado, Juan Antonio, La interpretación constitucional, en Revista Jurídica de Castilla y León 2 (2004), p. 72, sostiene que no existen diferencias fundamentales entre ambas, sin perjuicio de reconocer la mayor generalidad o abstracción de los principios sobre las reglas.

${ }^{73}$ Dworkin, Ronald, Judicial Discretion, cit. (n. 9), p. 25. 
puede o no existir, en cambio, para las reglas sí sería necesaria, las cuales ineludiblemente deben estar consagradas legislativamente ${ }^{74}$.

En cuanto a su estructura, siguiendo a Alexy, las reglas son normas que ordenan una consecuencia jurídica cuando se cumple el supuesto de hecho en ellas descrito, mientras que los principios son normas que admiten grados de realización. Así, los principios serían mandatos de optimización que ordenan que algo se cumpla en la mayor medida posible, esto es, por ejemplo, que se respete en la mayor medida posible la legalidad. En cambio, las reglas, que se aplican o no, no admiten - por su concreción-graduaciones.

En efecto, pareciera que la norma del Art. 64, que regula la comunicabilidad de circunstancias modificatorias de responsabilidad penal, no tiene ambiciones fundacionales o legitimadoras del sistema, caracteres de indeterminación o abstracción, ni ha sido llamada a iluminar ámbitos extensos de la legislación penal.

$\mathrm{Al}$ contrario, la norma — que como veremos, es propiamente una regla — tendría un propósito meramente utilitario y específico en el proceso de determinación de la pena para el caso concreto en cuanto a la valoración judicial de las circunstancias atenuantes o agravantes de responsabilidad que atañen a los intervinientes de un delito, sin perjuicio de que, a partir de la misma, se discuta latamente el contenido de la comunicabilidad.

Asimismo, la comunicabilidad en el Código sólo está expresada en el Art. 64. Así, de suprimirse dicho mandato, la norma y su contenido tenderían a desaparecer — como discusión específica sobre la comunicabilidad de circunstancias modificatorias-, pues no existen otras reglas que la consagren ${ }^{75}$, sin perjuicio de aquellas que tratan sobre la accesoriedad de la responsabilidad penal de los partícipes (en sentido estricto), v. gr., artículos 16 y 17.

En cambio, los principios propiamente tales, aun cuando no sean

${ }^{74}$ Pese a lo señalado, no existe un consenso doctrinal en cuanto a la absoluta distinción entre principios y normas. Así, y desde un prisma moderado: PRIETO SANCHIS, Luis, Sobre principios y normas. Problemas del razonamiento jurídico (Madrid, Editorial Centro de Estudios Constitucionales, 1992), pp. 83 y ss. Para un desarrollo más acabado de estas posiciones, ver Carbonell, Flavia - Letelier, Raúl, cit. (n. 7), pp. 158 y ss.

${ }^{75}$ En efecto y como postula Hernández Basualto, Héctor, cit. (n. 51), pp. 378 y 379: "siendo esa la única norma expresa sobre comunicabilidad en el derecho chileno y consagrando una solución tan nítida, resulta contraintuitivo que justamente en los casos en que la punibilidad de la conducta se funda en términos absolutos en la infracción de un deber especial y exclusivo del sujeto, la ley le asigne menos importancia al carácter personal de dicho deber y lo extienda indiscriminadamente a cualquiera". 
reconocidos formalmente, como ocurre en general, tenderían a permanecer inmanentes al sistema u ordenamiento jurídico penal, ya sea por su constelación de constituir fuentes del Derecho, establecer límites al ius puniendi, o fundar los pilares del Derecho penal moderno ${ }^{76}$.

En este sentido, parece correcta la estrategia del legislador penal al presentar los criterios sobre determinación de penas, y en lo que nos convoca, el del artículo 6477, al consagrar en el artículo 62 que: "Las circunstancias atenuantes o agravantes se tomarán en consideración para disminuir o aumentar la pena en los casos y conforme a las reglas que se prescriben en los artículos siguientes" ${ }^{\prime 7}$. Mismo vocablo - regla - utilizan los artículos 32 bis, 52 inciso $2^{\circ}, 60$ numeral $3^{\circ}$ y 61 numerales $1^{\circ}, 4^{\circ}$ y $5^{\circ}$, al tratar sobre la naturaleza, efectos y aplicación de las penas.

Sobre la expresa referencia a la categoría de reglas utilizada por el legislador y en los primeros comentarios al texto punitivo, se subrayaba que: “(...) el código ha necesitado establecer el sistema de reglas que se anuncia en este artículo, entre otros motivos, por la dificultad práctica de la materia" 79 .

Lo anterior pareciera cuestionar la naturaleza o cualidad de la comu-

${ }^{76}$ Así, y como se señaló al comienzo de este trabajo, el reconocimiento legislativo del principio no afectaría su concepción misma de principio, empero una mala técnica lo reglamente, aterrizándolo a casos concretos, generándose así una norma cuya validez, a juicio nuestro, derivaría de dicho principio. Así, la norma del Art. 18 de nuestro CP. regula en concreto el principio de irretroactividad penal al prescribir que: Ningún delito se castigará con otra pena que la que le señale una ley promulgada con anterioridad a su perpetración. Derogada que sea esta norma, ningún jurista en su sano juicio osaría proclamar el fin de este principio, aún inclusive se eliminara la norma constitucional que lo eleva a dicha categoría y reconocida en el numeral $3 .^{\circ}$ del Art. 19, pues el mismo responde a una ratio legis inmanente al Derecho Penal moderno y límite intrínseco al ius puniendi.

${ }^{77}$ Ello se puede constatar pues la norma se ubica geográficamente en el Párrafo Cuarto, Título III del Libro Primero del Código, denominado "De la aplicación de las penas", en conjunto de numerosas otra reglas de igual propósito, sin que exista norma alguna adicional que haga referencia directa a la comunicabilidad.

${ }^{78}$ Esta norma se tomó del artículo 67 del Código penal español de 1848-50, con muy similar redacción. Por cierto, el destacado es nuestro.

${ }^{79} \mathrm{El}$ destacado es nuestro. Vid. Fuensalidd, Alejandro, Concordancias y comentarios del Código penal chileno (Lima, Imp. Comercial Calle del Huallaga N. 139, 1883), I, pp. 285 y 286. Agrega el autor que "Si la lei al penar algunos delitos no hubiese tomado en cuenta determinadas circunstancias agravantes ni formado de estas delitos especiales en algunos casos; si no hubiera sido necesario imponer varios grados de pena a ciertos delitos por la variedad de accidentes i circunstancias que pueden concurrir; i si las atenuaciones i agravaciones fuesen todas de la misma entidad, mui breves $i$ mui sencillas serían las reglas de que vamos a ocuparnos; pero, siendo lo contrario, dichas reglas forman la parte mas importante i difícil de la penalidad". 
nicabilidad entendida como un principio, pues la norma que la regula, por su especificidad, estaría más bien llamada a resolver un problema concreto, esto es, regular la aplicación de las circunstancias atenuantes y agravantes que concurran al caso particular al determinar la pena. En este sentido, y de asumirse la naturaleza de principio de la comunicabilidad, ¿es posible extender la norma del artículo 64 a constelaciones que no regula?

Es sabido, y no se requiere ahondar mayormente, que una de las consecuencias más relevantes del denominado principio de legalidad es precisamente el mandato hermenéutico respecto de las disposiciones penales, que "prohíbe la analogía como medio de nueva creación y extensión de preceptos penales, así como la agravación de penas" y que por esto "el aplicador jurídico en Derecho penal está ligado más estrechamente a la proposición legal que en otros ámbitos del Derecho" ${ }^{80}$.

Así, la interpretación analógica o propiamente extensiva de una norma penal $^{81}$ no puede consistir en el ejercicio hermenéutico de aplicar uno

${ }^{80}$ Jescheck, Hans-Heinrich, Weigend, Thomas, Tratado de Derecho Penal. Parte General (traducción de Miguel Olmedo Cardenete, Granada, Comares, 2002), p. 143. Así también lo ha declarado la Excma. Corte Suprema, entre otros, en la sentencia recaída en la causa Rol No 5990-2004, de 20 de abril de 2005, Considerando Octavo: "Que el principio de legalidad, básico en el derecho penal, garantiza que sólo la ley, de alcance general y abstracto puede definir qué acción u omisión de una persona es punible como delito, estableciendo a la vez la pena que le corresponde al infractor, instituyéndose al efecto el principio de nullum crimen nulla poena sine proevia lege poenali que, como garantía penal, se consagra en la Carta Fundamental en el artículo 19 N. ${ }^{\circ}$ 3 inciso $7 .^{\circ}$ al establecer que: "ningún delito se castigará con otra pena que la que señale una ley", máxima que la doctrina unánime, refiere tanto a la descripción típica del hecho ilícito, como a la sanción que de manera estricta se señale al respecto de un determinado ilícito, para evitar, por supuesto, tanto la interpretación extensiva del precepto, como asimismo utilizar la analogía".

${ }^{81}$ Como lo expresa Jauchen, Eduardo, Derechos del imputado (Buenos Aires, Rubinzal-Culzoni Editores, 2005, Argentina), p. 91 y ss., la analogía es transportar la aplicación de una norma jurídica que regula una determinada conducta a otro caso cuyos supuestos de hecho son diferentes pero semejantes y, asimismo, que el legislador expresa con palabras sus preceptos, y de lo que no se desprenda de la literalidad de ellas no puede tener vigencia. Una ampliación del tenor literal menoscaba la autolimitación del propio Estado derivada de la Constitución. Agrega Jauchen que la prohibición de analogía tiene aplicación en la parte especial de la legislación penal en cuanto a la determinación literal del tipo y también respecto a la pena que se conmina. Por último, es fundamental tener presente que la analogía sí es permitida en el Derecho Penal sin restricción alguna cuando resulta favorable al imputado. Estos conceptos tienen plena vigencia en el caso de que se trata puesto que justamente el conflicto en que se ha puesto el fallo impugnado con la garantía invocada, lo ha sido por aplicar un tipo penal que se refiere al empleado público a quien a todas luces, ni aún desde un punto de vista normativo tiene ese carácter, puesto 
de los elementos integrantes del tipo - la calidad del sujeto activo- a personas que no tienen esa cualificación —empleado público en el caso presentado-, comunicando aquello que la norma no contempla en su enunciado como comunicable, pues el artículo 64 solo hace referencia a circunstancias modificatorias, mas no a elementos integrantes del tipo.

En efecto, y volviendo al caso expuesto al comienzo de este trabajo, una mala praxis jurisprudencial llevó al tribunal a quo —en aplicación de la comunicabilidad entendida como principio jurídico- a extender en términos amplios las cualidades personales del autor de un delito de fraude al Fisco - intraneus - a un coautor particular o no cualificado extraneus-, elevando a este último a la misma categoría que la del primero, quien para efectos punitivos fue considerado empleado público, con el correspondiente y considerable aumento de pena por la calificación de su condición particular.

Pese lo anterior, debemos destacar que la causa, al conocerse en sede de nulidad, contó con 2 votos disidentes, los que, a nuestro juicio, se acercan de mejor manera a la solución que se estima aquí adecuada. Así, y sin perjuicio de que el fallo fuese confirmado por la Corte Suprema, la sentencia contó con los votos disidentes de los Ministros Dolmestch y Künsemuller, quienes estuvieron por no aplicar la comunicabilidad de las circunstancias personales a los partícipes extraneus, limitando así la aplicación de la comunicabilidad, aunque sin cuestionar su calidad de principio.

Los ministros concluyeron que los partícipes extraneus debieron haber sido condenados por el delito de estafa del artículo 468 del CP., por tratarse el fraude al Fisco de un delito especial impropio, voto disidente que en su considerando cuarto expresó: Que existen estudios que con gran profundidad han abordado el tema de la comunicabilidad o incomunicabilidad en los delitos de malversación de caudales públicos y fraude al Fisco (Francisco Grisolía, Revista de Ciencias Penales, 3 a época, Enero-Junio 1975, No 1, T.XXX), evidenciando que el artículo 64 inciso $1^{\circ}$ del Código Penal resuelve negativamente, el caso de los partícipes extraneus en los delitos de malversación y fraude al Fisco, en el sentido que el vinculo funcionario no se comunica al particular que co-delinque con el empleado público, toda vez. que la calidad funcionaria es una circunstancia de carácter personal, que, al tenor del artículo 64 del Código Penal, sólo puede afectar a aquel en quien concurre ${ }^{82}$.

Un correcto entendimiento de la naturaleza y cualidad de la comuni-

que el artículo 260 del Código Penal ha definido los límites máximos hasta los cuales la norma penal por delito funcionario puede atrapar personas cuya calidad especial resultaba muy discutible, pero que sin ninguna duda, no resulta aplicable a los dos sentenciados recurrentes.

${ }^{82}$ Considerando cuarto, SCS, causa Rol No 17014-2015 de 17 de diciembre de 2015. Referencia de la corte hecha a Grisolía, Francisco, cit. (n. 30), pp. 3-47. 
cabilidad debiese llevarnos a una aplicación limitada y restringida de la misma solo respecto de aquellos casos que el legislador ha contemplado expresamente dentro de su constelación reguladora, ejercicio teórico que no se tiene presente al abordar los problemas que se suscitan a partir de la aplicación práctica de la disposición del artículo 64 .

$\mathrm{Al}$ contrario, concebir la comunicabilidad inconscientemente como un principio del Derecho, esto es, como un enunciado general y de elevado grado de abstracción, parece errado dadas las características y cualidades que la norma nos manifiesta. En efecto, los verdaderos principios del Derecho resultan inoperantes para la aplicación directa por subsunción en ellos ${ }^{83}$, función que parece característica del artículo 64 .

En este sentido, la constatación de un principio del Derecho no debiese provenir del mero uso inconsciente del vocablo asociado, en este caso, a la comunicabilidad. El surgimiento de los principios responde al ejercicio paciente del jurista, quien a través del desarrollo de la dogmática y evolución de la jurisprudencia lo rescata y evidencia, siendo reconocido y validado de manera general tras su consagración en el tiempo ${ }^{84}$. En consecuencia, su juridicidad no dependería exclusivamente de las formalidades legislativas sino de su intrínseco sentido de racionalidad o de su reconocimiento histórico-cultural que suponen algún valor, utilidad y, cierta necesidad $^{85}$, atributos que no se hallarían ni doctrinaria, ni jurisprudencialmente respecto a la comunicabilidad del Art. 64.

Lo que en definitiva resuelve la sentencia al condenar a los particulares extraneus como empleados públicos en calidad de autores de fraude al Fisco, fue aplicar de manera extensiva y sobre la base de una disposición de la parte general, un tipo penal que expresamente no fue concebido para particulares —analogía in malam partem ${ }^{86}$ - , transportando así el contenido regulatorio de una norma concreta (Art. 64) a sujetos no contemplados por el tipo en la parte especial (Art. 239). Esto, precisamente, por considerar

${ }^{83}$ En el mismo sentido, Sánchez-Ostiz, Pablo, cit. (n. 38), p. 18.

${ }^{84}$ Esser, al tratar sobre los principios y reglas (Principle and rule) en el Derecho del caso y refiriéndose a los sistemas anglosajones, postula que no se puede negar la influencia recíproca de la doctrina y la jurisprudencia en la formación de principios. Ello, señala el autor, se muestra sobre todo en la atención creciente que se presta a los dicta judiciales, que debaten doctrinariamente y adoptando actitudes de principio un determinado problema jurídico: cosa incompatible con las reglas técnicas de staredecisis, y sin embargo indispensable para la auténtica reelaboración de la regla. Esser, Joseph, cit. (n. 53), p. 254.

${ }^{85}$ En el mismo sentido, Yacobucci, Guillermo, cit. (n. 54), p. 101.

${ }^{86}$ En cuanto a la parte general y, volviendo a JAUCHEN, Eduardo, cit. (n. 81), pp. 91 y ss., "debe prohibirse la analogía a cualquier precepto que amplíe la punibilidad más allá de los tipos de la parte especial". 
la comunicabilidad como un principio, esto es, en términos amplios, generándose así importantes consecuencias jurídicas que colisionan peligrosamente con principios fundamentales del Derecho penal.

\section{CONCLUSIONES}

Se ha entendido de manera generalizada que la comunicabilidad en materia penal constituiría un principio del Derecho, sin que hasta ahora se haya cuestionado dicha cualidad. Esta categorización tiene relevancia en cuanto a la extensión de sus efectos y, en especial, para determinar el sentido y alcance de la norma del artículo 64 del CP. donde se expresa la comunicabilidad.

Son características de los principios su generalidad o amplitud, abstracción, constituir fuentes del Derecho y parámetros hermenéuticos frente a vacíos y lagunas legales, características que no se aprecian en la comunicabilidad expresada en el artículo 64, norma que, al contrario, tiene por objeto resolver aspectos concretos relacionados con el proceso de determinación de la pena, constituyendo, por tanto, una regla.

Considerar la comunicabilidad como un principio ha llevado a una aplicación extensiva que vulnera principios fundamentales de esta rama del Derecho, especialmente al extender la aplicación o contenido regulatorio de una regla concreta de la parte general a sujetos no contemplados por el tipo en la parte especial, vulnerando así la prohibición de analogía in malam partem y con ello el principio de legalidad.

A partir de la regla del artículo 64 se han esbozado distintas teorías que buscan explicar el contenido y alcance de la comunicabilidad. Todas estas hipótesis deben ser abordadas considerando, como punto de partida, que la norma del 64 es propiamente una regla -lo que implica una concepción y aplicación restringida de la comunicabilidad que allí se contiene- y no un principio del Derecho.

\section{BibLIOGRAFíA}

AlCALDE, Enrique, Los principios generales del Derecho (Santiago, Ediciones Universidad Católica de Chile, 2003).

Alexy, Robert, Teoría de la Argumentación Jurídica (traducción de Manuel Atienza e Isabel Espejo, Madrid, Centro de Estudios Constitucionales, 1997).

AleXY, Robert, Teoría de los derechos fundamentales (traducción de Carlos Bernal Pulido,

Madrid, Centro de Estudios Constitucionales, 1993).

Aristóteles, Ética Nicomáquea (Madrid, Gredos, 2000).

Bacigalupo, Enrique, Principios Constitucionales de Derecho Penal (Buenos Aires, Hammurabi, 1999).

Balmaceda, Gustavo, Comunicabilidad de la calidad del sujeto activo en los delitos contra la 
función pública: especial referencia a la malversación de caudales públicos y al fraude al fisco, en RDUCN 19 (2012) 2, pp. 45-81.

[visible en internet: http://www.scielo.cl/scielo.php?script=sci_arttext\&pid=S071897532012000200003\&lng=es\&nrm=iso]

Balmaceda, Gustavo - Castro, Carlos, Corrupción y delitos contra la administración pública. Especial referencia a los delitos de malversación de caudales y fraude al Fisco (Santiago, Editorial Librotecnia, 2015).

Baratta, Alessandro, Principios de Derecho Penal minimo. Para una teoría de los Derechos Humanos como objeto y límite de la ley penal, en Doctrina Penal. Teoría y Práctica en las Ciencias Penales 87 (2003), Año 10, pp. 623-650.

Bravo Lira, Bernardino, La fortuna del Código Penal español de 1848. Historia en cuatro actos y tres continentes: de Mello Freire y Zeiller a Vasconcelos y Seijas Lozano, en Anuario de Historia del Derecho Español 74 (2004), 23-58.

Bullemore, Vivian - Mackinnon, John, Curso de Derecho Penal. Parte Especial (2. ${ }^{\mathrm{a}}$ edición, Santiago, Editorial LexisNexis, 2007), IV.

Carbonell, Flavia - Coloma, Rodrigo - Letelier, Raúl (coordinadores), Principios Jurídicos, análisis y crítica (Santiago, Editorial Thompson Reuters, 2011) pp. 155-184.

Cury, Enrique, Derecho Penal. Parte General (2. ${ }^{a}$ ed., Santiago, Editorial Jurídica de Chile, 1992), II.

Cury, Enrique, Derecho Penal. Parte General (reimpresión de la 2. ${ }^{a}$ ed., Santiago, Editorial Jurídica de Chile, 1997), II.

Cury, Enrique, Derecho Penal. Parte General (8. ${ }^{a}$ ed., Santiago, Ediciones Universidad Católica de Chile, 2005).

Del Vecchio, Georgio, Los principios generales del Derecho (Lima, Ara Editores, 2006).

Dworkin, Ronald, Judicial Discretion, en The Journal of Philosophy 60 (1963) 21, p. 624. [visible en internet:

https://www.pdcnet.org/pdc/bvdb.nsf/purchase?openform\&fp=jphil\&id=jph il_1963_0060_0021_0624_0638]

Dworkin, Ronald, The Model of Rules, en The University of Chicago Law Review, 35 (1967) 1, p. 14. [visible en internet: http://chicagounbound.uchicago.edu/uclrev/vol35/ iss1/3/]

Etcheberry, Alfredo, Derecho Penal, Parte General (3. a edición, revisada y actualizada, Santiago, Editorial Jurídica de Chile, 1998), II.

Esser, Joseph, Principio y norma en la elaboración jurisprudencial del derecho privado. Título original: Grundsatz und Norm in der Richterlichen Fortbildung des Privatrechts (traducción de Eduardo Valentón Fiol, Barcelona, Bosch, 1961), 438 pp.

FERDMAn, Jorge, ¿De qué puede hacerse responsable al extraneus, concurrente a la comisión de un delito que requiere autor calificado? Comentario a propósito de algunos pronunciamientos jurisprudenciales chilenos en el ámbito de los delitos con sujeto activo calificado, en VAN WEEzEL, Alex (editor), Humanizar y renovar el Derecho penal. Estudios en memoria de Enrique Cury (Santiago, Legal Publishing, 2013), pp. $677-689$.

Fernández, Pedro Javier, Código Penal de la República de Chile, Esplicado y Concordado (2. ${ }^{a}$ edición, Santiago, Imprenta, Litografía y Encuadernación Barcelona, 1899).

Fuensalida, Alejandro, Concordancias y comentarios del Código penal chileno (Lima, Imp. Comercial Calle del Huallaga N. 139, 1883), I, 400 pp.

Gadamer, Hans-Georg, Verdad y Método I (11. a edición, Salamanca, Ediciones Sígueme, 2005). 
GaEte, Sergio, La comunicabilidad en torno a los elementos del delito, Memoria $\mathrm{N}^{\circ} 7$ (Santiago, Editorial Jurídica de Chile, 1963), 62 pp.

Garrido Montt, Mario, Etapas de ejecución del delito. Autoría y participación (Santiago, Editorial Jurídica de Chile, 1984), 453 pp.

García Amado, Juan Antonio, La interpretación constitucional, en Revista Jurídica de Castilla y León 2 (2004).

García Amado, Juan Antonio, Principios, reglas y otros misteriosos pobladores del mundo jurídico. Un análisis (parcial) de la Teoría de los derechos fundamentales de Robert Alexy, en Carbonell, Flavia - Coloma, Rodrigo - Letelier, Raúl (coordinadores), Principios Jurídicos, análisis y crítica (Santiago, Thompson Reuters, 2011).

GrIsolía, Francisco, La comunicabilidad en los delitos de malversación y fraude, en Revista de Ciencias Penales 34 (1975) 1, 3a época, pp. 3-47.

Gómez MarTín, Víctor, Delitos de posición y delitos con elementos de autoría meramente tipificadores: una distinción necesaria para los delitos especiales de funcionario, en Revista Doctrina y Jurisprudencia Penal 8 (2012), Año 3, pp. 3-44.

HenríQuez, Ian, La regla de la ventaja para el concebido en el Derecho Civil chileno (Santiago, Editorial Legal Publishing, 2011), 299 p.

Hernández Basualto, Héctor, Comentario al artículo 14, en Couso Salas, Jaime, HerNÁndez Basualto, Héctor (directores): Código Penal comentado. Parte General Doctrina y jurisprudencia (Santiago, AbeledoPerrot-LegalPublishing, 2011).

Jauchen, Eduardo, Derechos del imputado (Buenos Aires, Rubinzal-Culzoni Editores, 2005).

Jescheck, Hans-Heinrich, Weigend, Thomas, Tratado de Derecho Penal, Parte General (traducción de Miguel Olmedo Cardenete, Granada, Comares, 2002).

MaÑalich, Juan Pablo, La malversación de caudales públicos y el fraude al fisco como delitos especiales, en Política Criminal 7 (2012) 14, pp. 357 - 377.

MaÑALICH, Juan Pablo, ¿Discrecionalidad judicial en la determinación de la pena en caso de concurrencia de circunstancias atenuantes de la responsabilidad penal?, en Departamento de Estudios, Defensoría Penal Pública (2009)[visible en internet: http:/ / www.biblio.dpp.cl/biblio/DataBank/3767-2.pdf]

Maturana, Humberto - Varela, Francisco - Uribe, Roberto, Autopoiesis: The organization of living systems, its characterization and a model, en Biosystems 5 (1974) 4, pp. 187-196.

Novon, Eduardo, Curso de Derecho Penal chileno. Parte General (Santiago, Editorial Jurídica de Chile, 1960), II.

Novon, Eduardo, Curso de Derecho Penal Chileno (Santiago, Editorial Jurídica de Chile, 2005), II.

Ossandón Widow, María Magdalena, Delitos especiales y de infracción de deber en el Anteproyecto de Código Penal, en Política Criminal 1 (2006), A4, pp. 1-22.

Ossandón Widow, María Magdalena, Sobre la calidad de empleado público en los delitos funcionarios, en Revista Doctrina y Jurisprudencia Penal 8 (2012), Año 3, pp. 45-82.

Pacheco, Joaquín Francisco, El Código Penal Concordado y Comentado (6. ${ }^{\mathrm{a}}$ edición, corregida y aumentada, Madrid, Imprenta y Fundición de Manuel Tello, 1888), I.

Politoff, Sergio - Grisolía, Francisco - Bustos, Juan, Derecho Penal chileno. Parte especial. Delitos contra el individuo en sus condiciones físicas (2. ${ }^{a}$ edición, Santiago, Editorial Jurídica de Chile, 2006).

Politoff, Sergio - Matus, Jean Pierre - Ramírez, Maria, Lecciones de Derecho Penal cbileno. Parte General (2. edición, Santiago, Editorial Jurídica de Chile, 2004). 
Prieto SAnChIS, Luis, Sobre principios y normas. Problemas del razonamiento jurídico (Madrid, Editorial Centro de Estudios Constitucionales, 1992), 186 pp.

Rodríguez Collao, Luis - Ossandón Widow, María Magdalena, Delitos contra la función pública. El Derecho penal frente a la corrupción política, administrativa y judicial (Santiago, Editorial Jurídica de Chile, 2005).

Rodríguez Collao, Luis, Los principios rectores del Derecho Penal y su proyección en el campo de las circunstancias modificatorias de responsabilidad criminal, en Revista de Derechos Fundamentales (Universidad Viña del Mar) 8 (2012), pp. 145-172.

Rodríguez Collao, Luis, El principio de comunicabilidad en el ámbito de los delitos funcionarios, en Repositorio Digital del Fondo Nacional de Desarrollo Científico y Tecnológico (2004), FONDECYT. [visible en internet: http://dspace2.conicyt.cl/handle/10533/60566]

Rodríguez, Pablo, Teoría de la Interpretación Jurídica (Santiago, Editorial Jurídica de Chile, 2004), 182 pp.

Roxin, Claus, Autoría y dominio del hecho en Derecho penal (traducción de Joaquín Cuello Contreras y José Luis Serrano de Murillo, 7. a edición, Madrid, Marcial Pons, 1999).

SÁnchez-Ostiz, Pablo, Principios y reglas como base para un modelo argumentativo intercultural de Derecho penal, en Cornacchia, Luigi-Sánchez-Ostiz, Pablo, Multiculturalismo y Derecho penal (Pamplona, Thompson Reuters Aranzadi, 2012).

Sánchez-Ostiz, Pablo, Fundamentos de Política Criminal. Un retorno a los principios (Madrid, Marcial Pons, 2012).

Secretaría Técnica Comisión Foro Penal, Materiales de Estudio presentados a la Comisión Foro Penal, Parte General, en Política Criminal 1 (2006), D2.

SQuella, Agustín, Principios jurídicos y positivismo jurídico, en Carbonell, Flavia - ColoMA, Rodrigo - LeTELIER, Raúl (coordinadores), Principios Jurídicos, análisis y crítica (Santiago, Editorial Thompson Reuters, 2011), pp. 17-28.

Van Weezel, Alex, El sujeto activo del delito previsto en el art. $97 \mathrm{~N}^{\circ} 4 \mathrm{inc} .2^{\circ}$ del Código Tributario. Comentario de la sentencia de la Corte Suprema de $1^{\circ}$ de julio de 2008, causa Rol No 638-2008, en Jurisprudencia al día 101 (2008), Año III. [visible en internet: http://www.legalpublishing.cl/LSJ/extras/200811-1/pdfs/JAD_382.pdf]

Van Weezel, Alex, Lesiones y violencia intrafamiliar, en Revista Chilena de Derecho 35 (2008) 2, pp. 223 y ss.

Vargas, Tatiana, Manual de Derecho Penal Práctico. Teoría del delito con casos (2. ${ }^{\text {a }}$ ed., Santiago de Chile, Legal Publishing-Thomson Reuters, 2011).

Vargas, Tatiana, Comunicabilidad de circunstancias personales, en Jurisprudencia al dia 97 (2008), año 3.

Vergara Blanco, Alejandro, Los principios jurídicos y la tarea de construir el derecho administrativo en clave cientifica, en Revista de Derecho Administrativo 6 (2012), pp. 63-80.

Vergara Blanco, Alejandro, Delimitar y distinguir: teoría del derecho, filosofía del derecho y doctrina jurídica, en Revista de Derecho de la Pontificia Universidad Católica de V alparaíso 44 (2015), pp. 623-660.

YACOBUCCI, Guillermo, El sentido de los principios penales (Buenos Aires, Editorial BdeF, 2014).

Zaffaroni, Raúl (1987), Tratado de Derecho Penal (Buenos Aires, Ediar, 1987), I. 
JURISPRUDENCIA CITADA

SCS, causa Rol N 17014-2015, de fecha 17 de diciembre de 2015.

SCS, causa Rol N 638-2008, de fecha 1 de julio de 2008.

SCS, causa Rol No 1117-2008, de fecha 14 de octubre de 2008.

SCS, causa Rol No 4513-2010, de fecha 16 de octubre de 2010.

SCS, causa Rol No 9779-2010, de fecha 20 de abril de 2011.

SCS, causa Rol N ${ }^{\circ} 5419-2003$ de fecha 16 de octubre de 2006.

SCS, causa Rol N 25378-20014 de fecha 28 de junio de 2016.

SCS, causa Rol N²321-2007 de fecha 19 de mayo de 2008.

SCA de Talca, causa Rol N 441-2016, de fecha 11de julio de 2016.

SCA de Concepción, causa Rol N 152 de 2015, de fecha 27 de marzo de 2015.

SCA de Concepción, causa Rol N 566-2010, de fecha 13 de diciembre de 2010.

SCA de Valparaíso, causa Rol N 1182-2013, de fecha 30 de septiembre de 2013.

SCA de Temuco, causa Rol N 85-2007, de fecha 7 de febrero de 2008.

STC, Rol N² 2990, de fecha 10 de enero de 2017.

STC, Rol N 2988, de fecha 29 de diciembre de 2016.

STC, Rol No 3065, de fecha 27 de diciembre de 2016.

STC, Rol No 3091, de fecha 27 de diciembre de 2016.

STC, Rol No 3035, de fecha 27 de diciembre de 2016.

STC, Rol No 3141, de fecha 27 de diciembre de 2016.

STC, Rol N 3008, de fecha 27 de diciembre de 2016.

STC, Rol No 3052, de fecha 20 de diciembre de 2016.

STC, Rol No 2881, de fecha 15 de diciembre de 2016.

STC, Rol No 2874, de fecha 15 de noviembre de 2016.

STC, Rol N 2953, de fecha 4 de octubre de 2016.

STC, Rol N² 2922, de fecha 29 de septiembre de 2016.

STC, Rol No 2744, de fecha 8 de octubre de 2015.

STC, Rol N² 2673, de fecha 1 de octubre de 2015.

STC, Rol No 2648, de fecha 7 de septiembre de 2015.

STC, Rol No 2615, de fecha 30 de octubre de 2014.

STC, Rol No 1973, de fecha 3 de noviembre de 2011.

STC, Rol No 1584, de fecha 17 de junio de 2010.

STC, Rol No 559, de fecha 7 de junio de 2007.

STC, Rol No 468, de fecha 9 de diciembre de 2006.

STC, Rol N 3000, de fecha 10 de enero de 2017.

STC, Rol N 2983, de fecha 13 de diciembre de 2016.

STC, Rol N² 2896, de fecha 25 de agosto de 2016.

STC, Rol N 2722, de fecha 15 de octubre de 2015.

STC, Rol N ${ }^{\circ} 2744$, de fecha 8 de octubre de 2015.

STC, Rol No 2702, de fecha 11 de junio de 2015.

STC, Rol No 2346, de fecha 16 de enero de 2014.

STC, Rol N 2402, de fecha 26 de noviembre de 2013.

STC, Rol No 2403, de fecha 8 de noviembre de 2013.

STC, Rol N 2133, de fecha 4 de julio de 2013.

TOP Los Andes, causa Rit N 18-2015, de fecha 19 de septiembre de 2015. 